\title{
Capture the variation of the pore pressure with different geological age from seismic inversion study in the Jaisalmer sub-basin, India
}

\author{
Raman Chahal ${ }^{1} \cdot$ Saurabh Datta Gupta ${ }^{1}$
}

Received: 5 January 2020 / Accepted: 30 June 2020 / Published online: 20 October 2020

(c) The Author(s) 2020

\begin{abstract}
Geoscientific evidence shows that various parameters such as compaction, buoyancy effect, hydrocarbon maturation, gas effect and tectonic activities control the pore pressure of sub-surface geology. Spatially controlled geoscientific data in the tectonically active areas is significantly useful for robust estimation of pre-drill pore pressure. The reservoir which is tectonically complex and pore pressure is changing frequently that circumference motivated us to conduct this study. The changes in pore pressure have been captured from the fine-scale to the broad scale in the Jaisalmer sub-basin. Pore pressure variation has been distinctly observed in pre- and post-Jurassic age based on the current study. Post-stack seismic inversion study was conducted to capturing the variation of pore pressure. Analysis of low-frequency spectrum and integrated interval velocity model provided a detailed feature of pore pressure in each compartment of the study area. Pore pressure estimated from well $\log$ data was correlated with seismic inversion based result. Based on the current study one well has been proposed where pore pressure was estimated and two distinguished trends are identified in the study zone. The approaches of the current study were analysed thoroughly and it will be highly useful in complex reservoir condition where pore pressure varies frequently.
\end{abstract}

Keywords Pore pressure $\cdot$ Seismic inversion $\cdot$ Clastic and carbonate reservoir

\section{Introduction}

The current study has been concentrated in the Jaisalmer sub-basin area of Rajasthan basin (Fig. 1). The Jaisalmer sub-basin is a matured basin for hydrocarbon exploration. It has been assumed that hydrocarbon has migrated from the Indus basin (Bourah 2010) to the Rajasthan basin in the Cretaceous age. Six major geological formations are present in this area namely, Goru, Pariwar, Bedesir-Baisakhi, Jaisalmer, Lathi and Shumarwali.

The reservoir character of this area is the culmination of clastic and carbonate sequences (DGH). Both clastic and carbonate sequence acts as a reservoir rock in the Jaisalmer

Edited by Jie Hao

Saurabh Datta Gupta

saurabh.doc.ism@gmail.com

Raman Chahal

ramanchahal75@gmail.com

1 Department of Applied Geophysics, Indian Institute of Technology (Indian School of Mines), Dhanbad, Dhanbad, Jharkhand 826004, India sub-basin. The Jaisalmer limestone is a carbonate sequence and the impactful reservoir for this basin (GSI report on a petrographic study by Bhushan, 1966). A comparatively thin section of the shale unit of Bedesir-Baisakhi formation acts as a cap rock of this limestone reservoir. It has been observed that there are lack of significant hydrocarbon explorations in this sub-basin area due to the complex reservoir structure and presence of discrete facies. This set-up is related to major tectonic activities in this area (Biswas 1987, 2012) (Fig. 2). Generally, pore pressure in normal conditions is in the hydrostatic state of water stored in the pore system. Any kind of deviation from this hydrostatic pore pressure gradient will be tricky for drilling of an exploratory well. This deviation is known as abnormal pressure, which can be more or less of the hydrostatic pore pressure gradient. This phenomenon generates due to various reasons such as compaction, density differentiation of rock particles, fluid transportation or digenesis process (Oil field review). Abnormal overpressure is involved in the hydrocarbonbearing reservoir where one zone sealed from other zones based on the structural and depositional configuration of the reservoir (Singha and Chatterjee 2014; Merey 2020; Hussain and Ahmed 2017). It is observed that pore water 


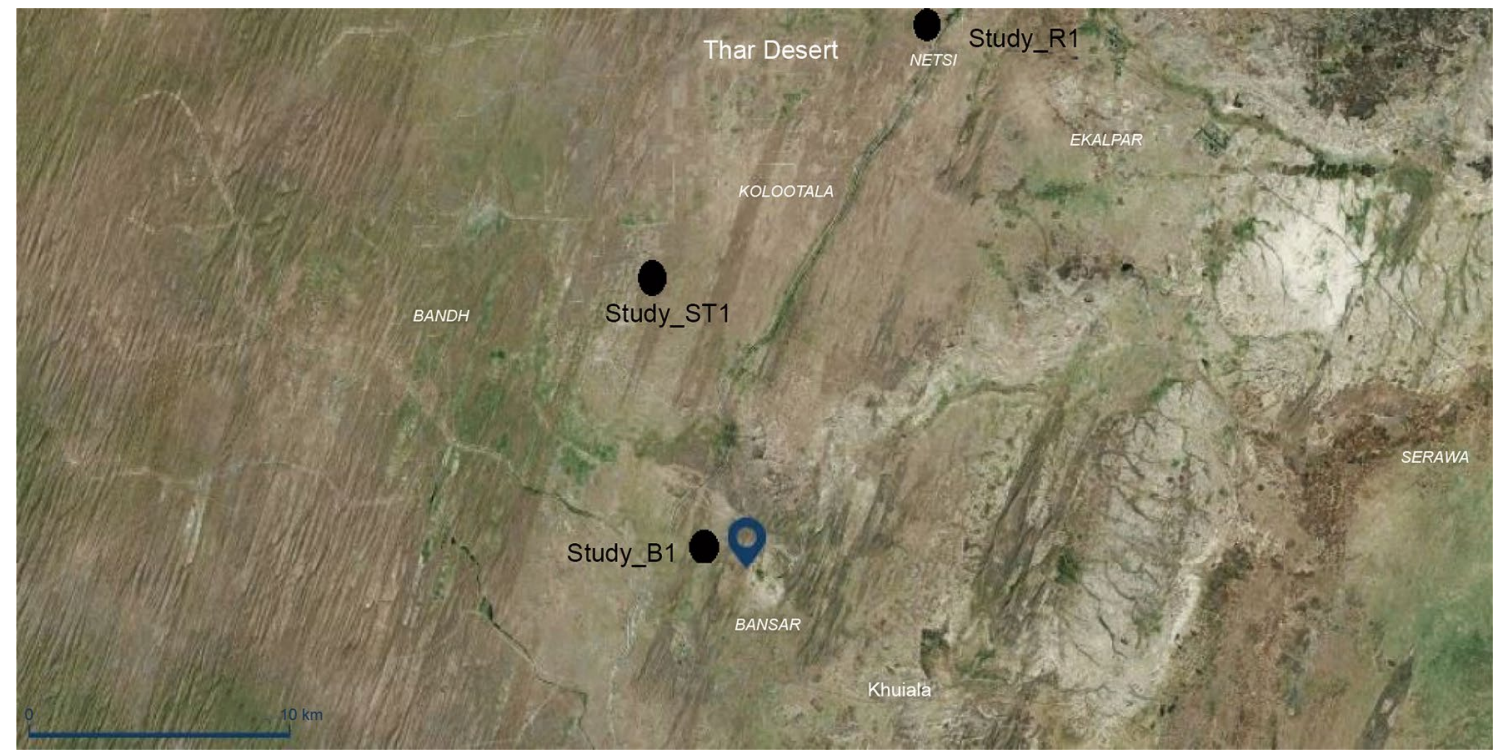

Fig. 1 The study well locations are placed in the geographic map of the Jaisalmer sub-basin a part of Rajasthan basin

trapped in rock pore space and the seal created before pore water is eliminated from the pore space of reservoir rock and as a consequence overpressure is developed (Das and Chatterjee 2018). Other possibilities to create subnormal or low-pressure zone are where the water table is quite deep (approximately below more than $300 \mathrm{~m}$ ) or in the depletion stage of the hydrocarbon-bearing reservoir. It may be noted that not maintaining the reservoir pressure or leakage in reservoir rock is also the cause of low pressure due to the high production of hydrocarbon fluid (Singha et al. 2014).

The current study is related to geomechanical and petroelastic property analysis of the reservoir (Adouani et al. 2019). This study has been focused on the area where the chance of discovery for the newly proposed drill well is high. The basic idea of estimation of pore pressure has been framed based on famous effective stress law of Terzaghi's and Biot's (Terzaghi et al. 1996; Biot 1954). This effective stress law states that the pore pressure of a formation can be estimated based on overburden and effective stress. Most of the pore pressure estimation is conducted based on well log data where overburden stresses are estimated based on bulk density logs. The effective stresses are calculated from resistivity, P-sonic or compressional velocity and bulk density $\log$ data (Zhang 2011). Use of drilling parameters is a significant step for stress estimation. A theoretical model (Zhang 2011) was introduced between pore pressure and porosity based on the pressure generation mechanism for estimating pore pressure from well log data. Pore pressure was estimated using 2D seismic and relevant well log data (Noori et al. 2014) with the help of Eaton's (Eaton 1969, 1972) and Bower's relation (Bowers 1995, 2001, 2002). Distinct pore pressure variations were observed in an unstable zone with the presence of folding and faulting structure (Qays and Wan 2015). Real-time pore pressure measurement is another milestone under this segment (Zhang and Yin 2017). Resistivity, P-sonic travel time or corrected d-exponent methods are the major procedure for the real-time measurement.

In this study, we have considered both structural and sedimentary component together through 3D post-stack seismic inversion analysis. Wide range of structural complexity with faults and high aperture fractures is observed in our study area. The current study has shown the pore pressure variation with geological age. Detailed analysis of seismic lowfrequency model and integration between seismic and well $\log$ analysis has produced a robust result in the field of pore pressure estimation in our study.

It has been found that all the three wells are not hydrocarbon bearing. Although the signature of residual oil is identified in the well Study_R1 and Study_B1. The presence of residual oil probably developed due to leakage in the reservoir. The presence of a water table in the deeper strata has been identified which can replace the hydrocarbon of the reservoir through the leakage due to pressure differences. This is another interesting part to take this study. Useful information is accumulated from drilled well data, geological study and seismic data for conducting this study. Relevance and correctness of available information are analysed for pore pressure analysis based on the geological setting of the study area. The significant result of this study states the importance of post-stack seismic inversion. Other than poststack seismic inversion, three wells (Study_R1, Study_ST1 and Study_B1) are considered to estimate the pore pressure in this study. All three wells are vertically drilled. Significant focus on low-frequency and ultra-low frequency model in 


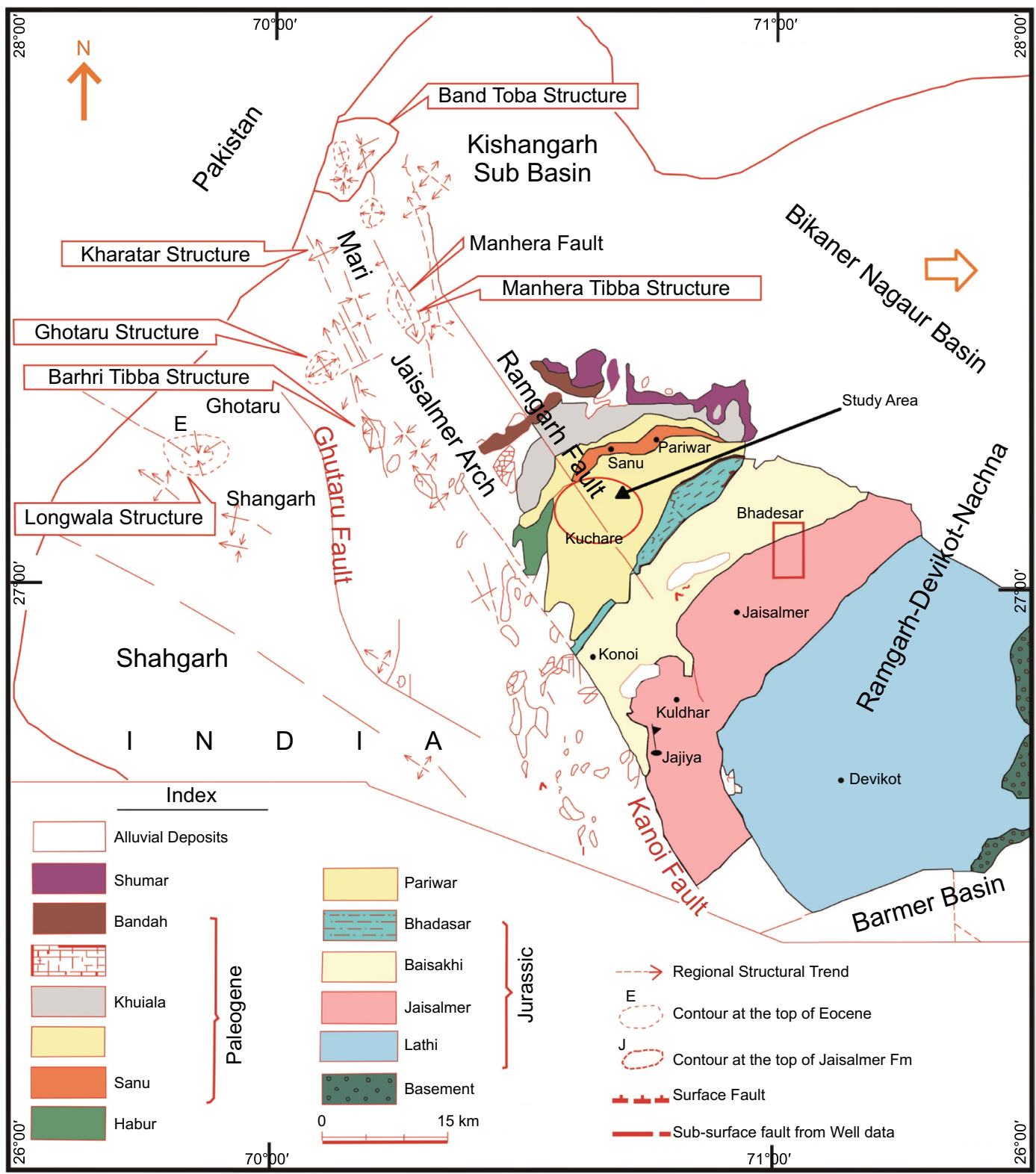

Fig. 2 The study area has been marked over a tectonic and sedimentary map of the Jaisalmer sub-basin, a part of the Rajasthan basin (modified after Pandey et al. 2009a, b)

seismic inversion study establish a good correlation of pressure trend in between the study wells. The integrated results show the importance of the present adopting approach in high tectonically active areas. The study shows the changes in formation and fracture pressure in the Jaisalmer carbonate reservoir. The pressure variation captures the variation of rock physical and petrophysical properties of the reservoir. Pore pressure variation in pre- and post-Jurassic age is significantly observed from this study with depositional history. This full phase work will represent the holistic view of the complex sub-surface geology of the reservoir with all reservoir components.

\section{Methods and data used}

\subsection{Pore pressure estimation}

In these three drilled study wells, all necessary data are available to conduct this study. Available data are mentioned in Table 1 as a summary form.

All three wells are vertically drilled. All three wells were drilled more than $2000 \mathrm{~m}$ and well log data were collected up to drilled depth (TD). Our study zone was selected from the Bedesir-Baisakhi formation to the top of the Lathi formation. The selection was made based on 
Table 1 Available dataset in the study area for conducting pore pressure study

\begin{tabular}{lll}
\hline Well name/other data & Nature of data & Availability \\
\hline Well Study_R1 & 1. Open Hole well log data_GR, RHOB, LLD, NPHI, DT, CALI & 1. Available \\
& 2. Pressure data & 2. Available \\
Well Study_ST1 & 1. Open Hole well log data_GR, RHOB, LLD, NPHI, DT, CALI & 1. Available \\
& 2. Pressure data & 2. Available \\
Well Study_B1 & 1. Open Hole well log data_GR, RHOB, LLD, NPHI, DT, CALI & 1. Available \\
Report & 2. Pressure data & 2. Not available \\
Map and reports & Well details in form of well Study_B1 completion report & Available \\
Post-stack seismic & Geological information—-structural, stratigraphical and lithological etc. & Available \\
\hline
\end{tabular}

Table 2 Major markers encountered by well Study_R1, Study_ST1 and Study_B1 in the study area

\begin{tabular}{llc}
\hline Well name & Formation name & Depth in MD, m \\
\hline Well Study_R1 & Bedesir-Baisakhi & 745 \\
Well Study_R1 & Jaisalmer & 1225 \\
Well Study_R1 & Lathi & 1694 \\
Well Study_ST1 & Bedesir-Baisakhi & 1137 \\
Well Study_ST1 & Jaisalmer & 1533 \\
Study_ST1 & Lathi & 2057 \\
Study_B1 & Bedesir-Baisakhi & 736 \\
Study_B1 & Jaisalmer & 1210 \\
Study_B1 & Lathi & 1690 \\
\hline
\end{tabular}

changes in the geological age such as the Jurassic to the Cretaceous.

All processed field acquired well log data was petrophysical corrected, and the bad hole or spurious data were removed prior to the pore estimation process. The relevant well log data of two wells (Study_R1 and Study_B1) covers the full zone of study, i.e. from the top of BedesirBaisakhi to top of Lathi formation. However, useful well log data for Study_ST1 well is limited to the Bedesir-Baisakhi formation only. All three wells were used for seismic inversion study.

Various approaches were adopted for pore pressure measurement based on available well data. These approaches are based on velocity and or resistivity parameters of the reservoir formation due to under compaction. It was observed that distinct pressure changes are present between the shale section and the non-shale section in the study area. These are due to grain size differentiation in the formation which is related to fluid mechanics. Although this study was concentrated only on the Bedesir-Baisakhi clastic and the Jaisalmer limestone formation which comes under non-shale classification; however, cumulative effects of shale section can be experienced. Table 2 is showing the depths encountered by well Study_R1, Study_ST1 and Study_B1 for major markers in the study area.

Clastic rich deep Shumarwali formation was drilled by both the well_-Study_R1 and Study_B1, whereas Study_ ST1 was drilled up to lower part of the Jaisalmer formation. Figure 3 shows a correlation between major formations of three wells in the study area through conventional well log data. Distinguished lithological variation has been observed with depth.

The oldest drilled well of the study area was Study_R1, the GR log of the well shows (Fig. 4) the prominent changes in lithology. A fine level of lithology classification was carried out based on the cut-off of GR log which shows the sandstone and limestone dominance in the Bedesir-Baisakhi and the Jaisalmer formation (Fig. 5). The Jaisalmer formation was mainly deposited by fossiliferous limestone with few portions of the intercalation shale and sandstone section. This lithological variation provides a strong background of pressure changes in reservoir formation which is also related to overburden stress. We have estimated the overburden stress for pore pressure estimation and fracture gradient calculation through a curve matching process. This estimation was restricted in the Jaisalmer formation only. Equation 1 was used for the estimation of overburden stress in the form of vertical stress. Initially, the differential variation of formation density with depth was estimated and in the next stage, the variations were integrated to capture the full variation of stress according to the following equation (Zang and Stephansson 2010; Najibi et al. 2017; Alam et al. 2018).

$\sigma_{\mathrm{v}}=\int_{0}^{z} \rho(z) \cdot g \cdot \mathrm{d} z$

where $\sigma_{\mathrm{v}}$ is considered as vertical stress, whereas $\rho$ is density and $g$ is considered as acceleration due to gravity.

Pore pressure can be measured from direct methods such as MDT. Apart from the direct method, it can be measured based on well log data which are related to 


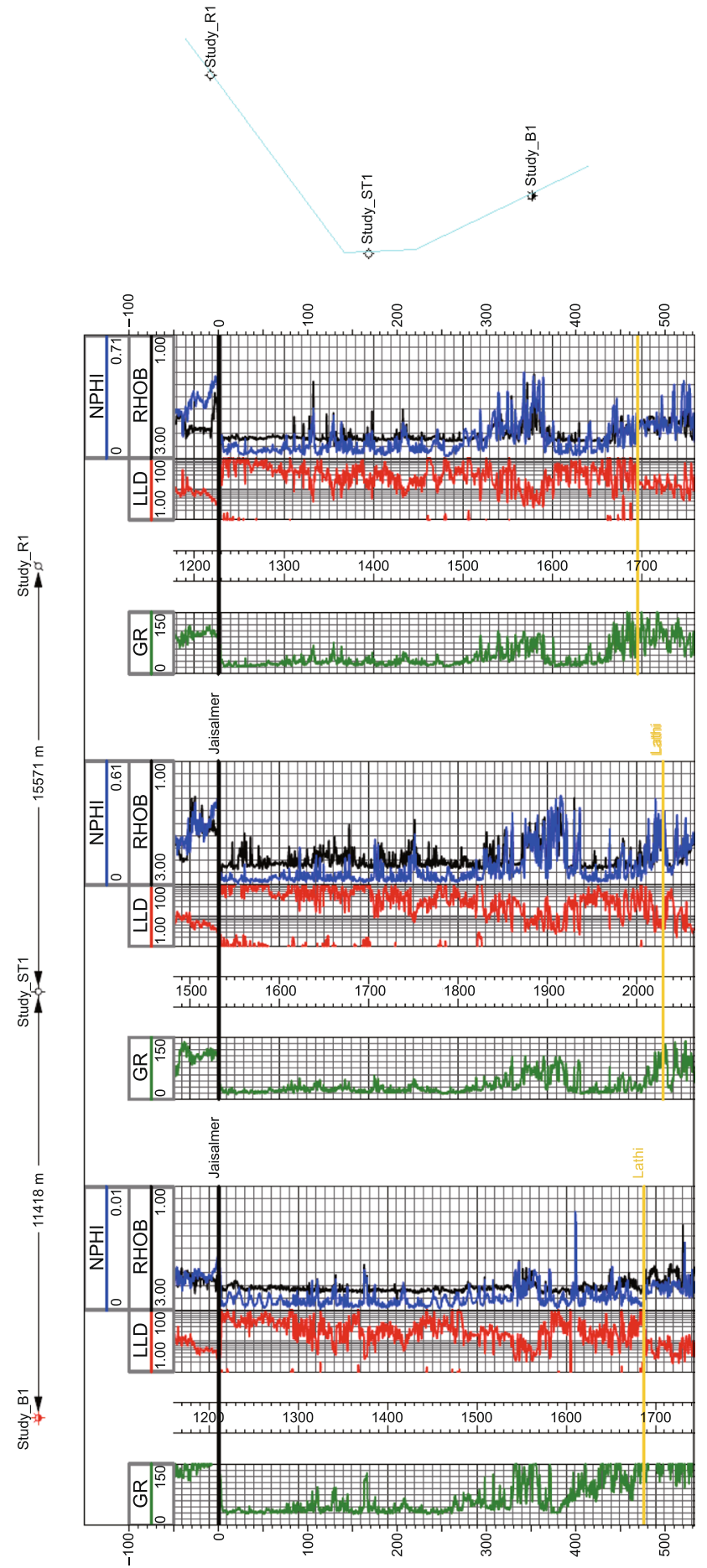

Fig. 3 Distinguishable geological features have been identified through the well correlation of study wells (Study_R1, Study_ST1 and Study_B1) in between the Jaisalmer and the Lathi formation

porosity (LLD, DT, etc.) for shale formation. In the Jaisalmer formation, intercalation of shale formation with the Jaisalmer limestone is found. The power law was used for vertical stress calculation based on curve matching procedure. This law captures the relative changes between two variables (Reed-Hill et al. 1995; Keller et al. 2014). Equations 2 and 3 are used for this purpose where extrapolation of density log estimated available density log of different depth to mudline for curve matching is given by (Zhang 2011)

$\Phi_{\mathrm{np}}=\varphi_{\mathrm{s}} \exp \left(-K \sigma_{\mathrm{v}}\right)$

where $\Phi_{\mathrm{np}}$ is considered as porosity in normal pressure condition in the shale section and $\varphi_{\mathrm{s}}$ porosity of shale in surface condition; $K$ is constant and $\sigma_{\mathrm{v}}$ is vertical stress

$\Phi_{\mathrm{np}}=\varphi_{\mathrm{s}} \exp \left(-K\left(\sigma_{\mathrm{ov}}-P_{\mathrm{p}}\right)\right)$

where $\sigma_{\mathrm{ov}}$ is considered as overburden stress and $P_{\mathrm{p}}$ is known as pore pressure.

Equations 2 and 3 can be converted to following expression based on power law

$P=\rho_{x}+A *(\text { TVD-WD-AG })^{\alpha}$

where $\mathrm{WD}=$ water depth and $\mathrm{AG}=$ air gap; $\rho_{x}, A$ and $\alpha$ are fitting parameter for curve matching.

Velocity and porosity are related to effective stress. It can be said that the velocity of the formation increases due to a decrease of formation rock porosity which is related to the loading of sediments of the formation, whereas the same will increase in normal compaction scenario at the boundary of different grain density of the formation (Dasgupta et al. 2016). It has been observed that velocity increases with depth in normal pressure conditions and this trend line is known as normal compaction trend line (NCTL) which is also known as hydrostatic pressure (Hottman and Johnson 1965). DT (P-sonic) log is used for velocity estimation purposes at well level, whereas seismic velocity is used for spatial control purposes towards NCTL measurement (Pennebaker 1968). NCTL is a standard compaction trend line and any deviation from this line is known as changes of pressure. Since velocity is an important parameter for pore pressure measurement through compaction analysis hence effective stress can be estimated from total stress and pore pressure using a variation of velocity (Terzaghi and Peck 1948). Using Eq. 5 effective stress is calculated using (Zhang 2011)

$\sigma^{\prime}=\sigma_{\mathrm{v}}-P_{\mathrm{p}}$

where $\sigma^{\prime}$ is considered as effective stress, whereas $\sigma_{\mathrm{v}}$ is the total stress (considered vertical component) and $P_{\mathrm{p}}$ is pore pressure.

Eaton's method was used here to estimate the pore pressure. P-Sonic velocity was directly measured from field and deviation w.r.t NCTL was captured to estimate the pore pressure variation (Eaton 1975). Using following expression, overburden stress (vertical component) was estimated in 


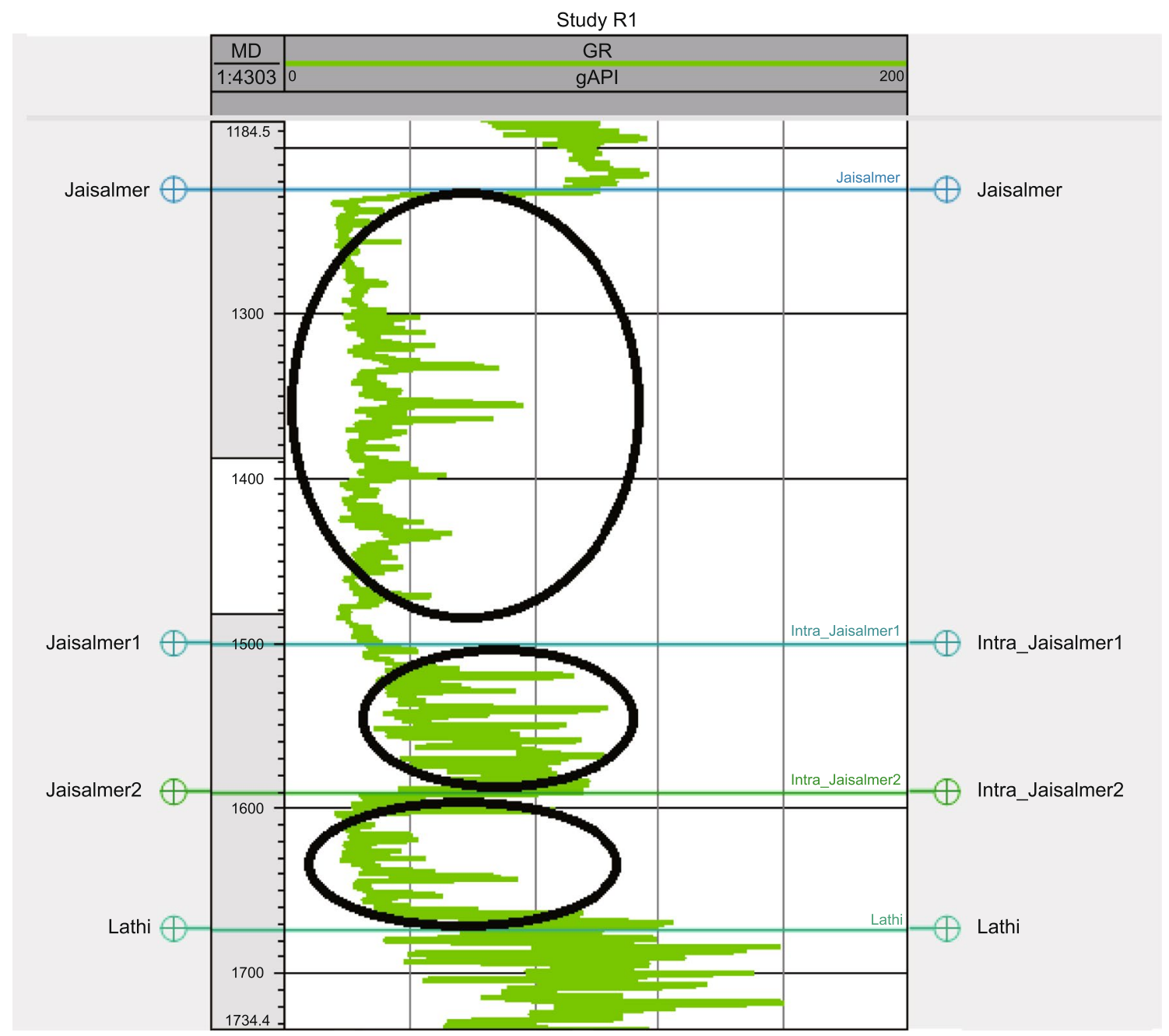

Fig. 4 Significant changes in the finer level of the geological formations have been captured with depth through GR (gamma-ray) log data variations in Study_R1 well

connection with a variation of velocity (Eaton 1972, 1975; Das and Chatterjee 2018).

$\sigma_{\mathrm{v}}^{\prime}=\left(\sigma_{\mathrm{v}}-P_{\text {norm }}\right) *\left(V / V_{\text {norm }}\right)^{n}$

where $P_{\text {norm }}$ is normal hydrostatic pressure and $V_{\text {norm }}$ is showing the corresponding velocity of the particular depth; $V$ is the measured velocity at a particular depth.

Replacing Eq. 5 in Eq. 6 with effective stress term (Eaton 1972, 1975; Zhang 2011)

$P_{\mathrm{p}}=\sigma_{\mathrm{v}}-\left(\sigma_{\mathrm{v}}-P_{\text {norm }}\right) *\left(V / V_{\text {norm }}\right)^{n}$

where $n$ is known as Eaton exponent and its value is considered as 3. After the estimation of pore pressure values, the NCTL has been modified based on measured pore pressure information to get the robust pore pressure estimation of the formation for the study wells. This outcome was calibrated from mud weight, formation pressure and fracture pressure data with the help of LOT/FIT data (leak of test/formation integrity test) for the wells Study_R1 and Study_ST1. LOT data are available in nearby offset well of Study_R1. To estimate the formation pressure, RFT (repeat formation tester) was carried out through RDT (reservoir description tool) in the well Study_B1. These data were used to calibrate outcome of this study in the well.

\subsection{Fracture pressure estimation}

Hubbert and Willis (1957) have invented a perception on minimum injection pressure. This perception was used by Eaton (1969) towards estimation of fracture gradient with the help of Poisson's ratio (Zhang and Yin 2017).

$\mathrm{FG}=v /(1-v) *\left(\mathrm{OBG}-P_{\mathrm{p}}\right)+P_{\mathrm{p}}$ 


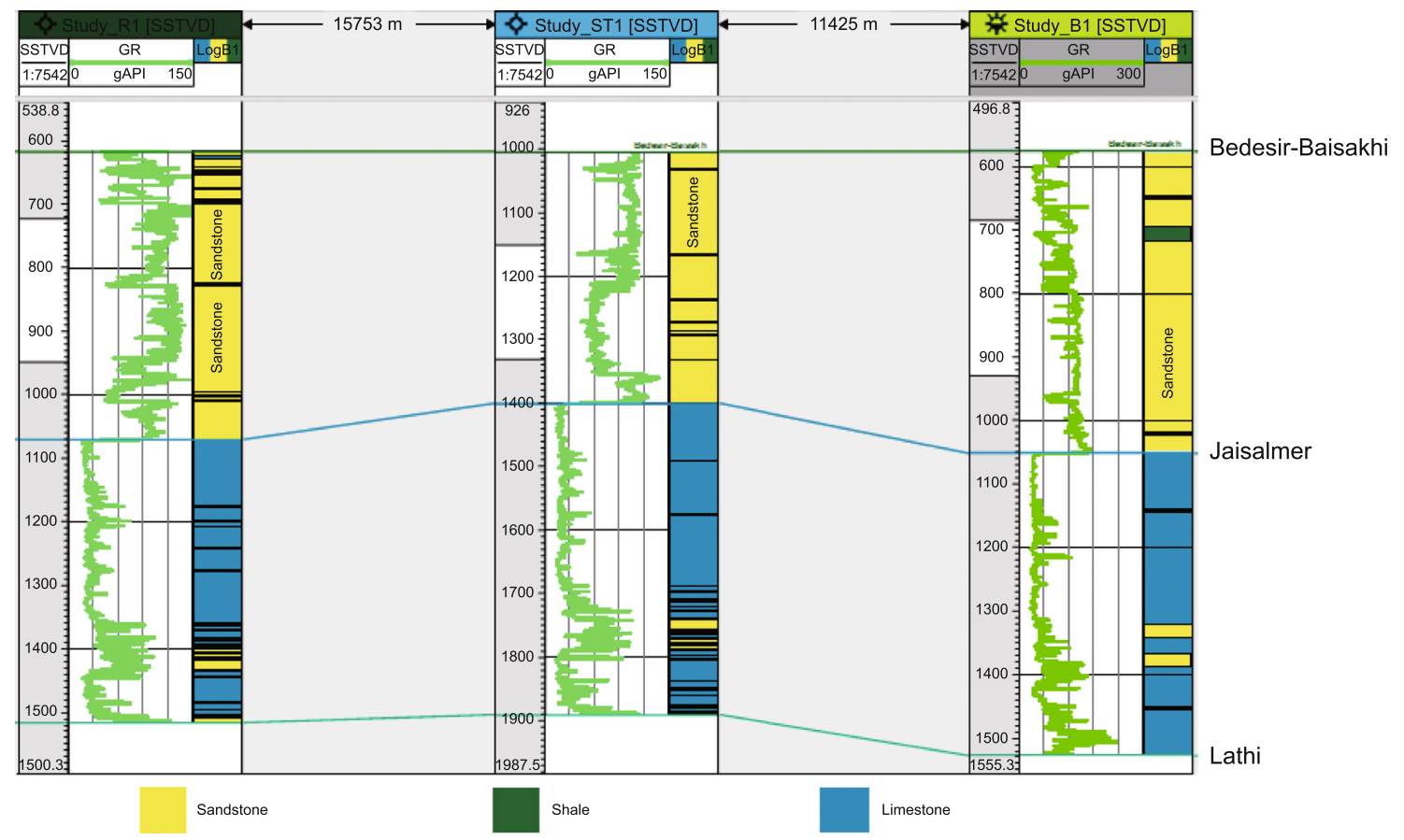

Fig. 5 Identification of lithofacies in the study well based on GR (gamma-ray) log cut-off; the figure shows the presence of sandstone, limestone and shale in between study zone from the Bedesir-Baisakhi to the Jaisalmer formation

FG is the fracture gradient; $\nu$ is Poisson's ratio; OBG is overburden stress and $P_{\mathrm{p}}$ is pore pressure.

Poisson's ration was estimated based on following expression (Hussain and Ahmed 2017).

$v=1 / 2 *\left(V_{\mathrm{p}}^{2}-2 V_{\mathrm{s}}^{2}\right) /\left(V_{\mathrm{p}}^{2}-V_{\mathrm{s}}^{2}\right)$

Equation (9) shows that for capturing the lithological variations such as sandstone, shale and limestone is crucial for estimation of Poisson's ratio hence same also consider for estimation of fracture gradient from Eaton's method in uniaxial stress scenario (Zhang and Zhang 2017).

The following expression was also incorporated in this study for estimating of fracture pressure (Hussain and Ahmed 2017) based on Poisson's ration, overburden pressure and pore pressure.

$\mathrm{FP}=3 v * 3 v / 2(1-v) *\left(\mathrm{OBP}-P_{\mathrm{p}}\right)+P_{\mathrm{p}}$

P-sonic was available in all three wells; however, S-sonic or S-velocity data were available in Study_B1 well only. S-velocity data for the well Study_R1 and Study_ST1 well were estimated based on empirical relationship (Hussain and Ahmed 2017; Mathew and Kelly 1967). We have used three empirical relations to get the best fit option such as Greenberg and Castagna (1992), Freund (1992) and Krief (1990). The relations are mentioned below (Hussain and Ahmed 2017).
Greenberg and Castagna relation:

$V_{\mathrm{s}}(\mathrm{km} / \mathrm{s})=0.8042 V_{\mathrm{p}}-0.8559$

Freund relation:

$V_{\mathrm{s}}(\mathrm{km} / \mathrm{s})=0.763 V_{\mathrm{p}}-0.603$

Krief relation:

$V_{\mathrm{s}}^{2}(\mathrm{~km} / \mathrm{s})=\left(V_{\mathrm{p}}^{2}-4.894\right) / 2.033$

However, based on lithology of the study area and grains size of rock sample Greenberg and Castagna (1992) was most relevant for estimating S-wave velocity (Fig. 6). Few points of $\mathrm{P}$-sonic data were badly affected in the bottom part of Bedesir-Baisakhi formation in Study_ST1 well. These badly affected points were removed and based on Gardner's relation (Gardner et al. 1974) these points are replaced with estimated P-sonic values where both the constants of Gardner's relation ( $\mathrm{a}$ and $\mathrm{b}$ ) are considered as 0.31 and 0.25 , respectively.

LOT data were collected from the offset well of Study R1 which was used to calibrate with measured fracture pressure from Eaton's method. Leak of test data shows good correlation between measured and acquired estimation of fracture pressure. 

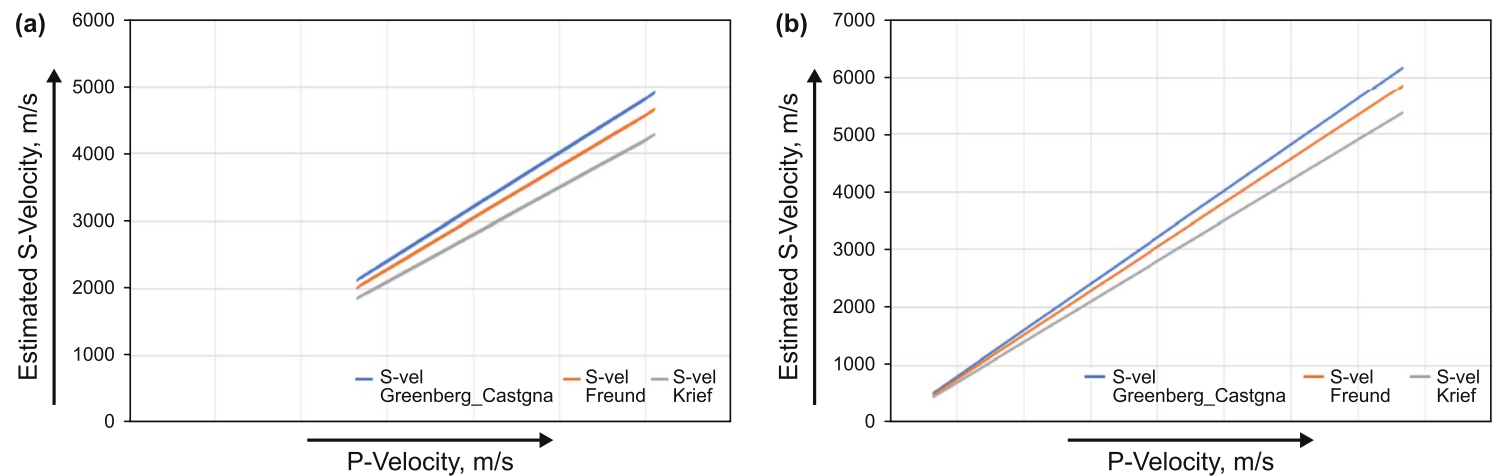

Fig. 6 Graphical representation of estimated S-velocity from P-velocity based on empirical relationship; "Blue" line shows S-velocity estimation based on Greenberg-Castagna empirical relation; "Orange" line shows S-velocity estimation-based Freund empirical relation; S-velocity estimation based on Krief empirical relation generates through "Grey" line; a the relation of the well Study_R1; $\mathbf{b}$ the relation of the well Study_ST1

\subsection{Seismic inversion study}

Variations of pore pressure in the study area of the Jurassic and the Cretaceous age were estimated from drilled well data. Estimation of pore pressure from drilled well data was restricted to a certain position. To get the overall picture of pressure variation in the study area, a good correlation between drilled well data and spatially controlled data is required.

In this study, we have used post-stack seismic inversion result as spatial controlled data. Seismic inversion is a process which converts interface property to a layer property of sub-surface geology. In the study area, seismic data quality is considered as moderate to the fair. Seismic data develop an unbiased lithological correlation in between drilled well areas. In this study, post-stack seismic inversion result was used widely for identifying the proposed location based on pressure estimation of a different lithological unit. A feasibility study was conducted before conducting a post-stack seismic inversion analysis. The following data (Table 3) was used for the post-seismic inversion study.

Table 3 shows the possibilities of seismic inversion study for both pre-stack and post-stack. However, due to poor data quality in offset seismic only post-seismic inversion study was carried out. Estimated S-sonic based on empirical relation may produce biases in the result particularly away from the drilled wells. The judgement of data quality was performed based on feasibility study of the various angle stack seismic data. Amplitude-frequency spectrum analysis has represented limited response in the reservoir section for angle stack seismic data. Amplitude spectrum analysis has produced frequency distribution of the full stack seismic data which is varying from 8 to $67 \mathrm{~Hz}$. The distribution pattern shows a considerable variation of frequency in the study zone.

The necessary petrophysical properties ( $\varphi$ and $S_{\mathrm{w}}$ ) were estimated in connection with pore pressure estimation
Table 3 Available dataset in the study area for conducting seismic inversion study

\begin{tabular}{lll}
\hline Well name/other data & Type of data & Availability \\
\hline Well Study_R1 & Compressional Sonic (P-sonic) & Yes \\
& Shear Sonic (S-sonic) & No \\
& Density (RHOB) & Yes \\
Well Study_ST1 & Compressional Sonic (P-sonic) & Yes \\
& Shear Sonic (S-sonic) & No \\
& Density (RHOB) & Yes \\
Well Study_B1 & Compressional Sonic (P-sonic) & Yes \\
& Shear Sonic (S-sonic) & Yes \\
& Density (RHOB) & Yes \\
Pre-stack Seismic & Angle stack data & Yes \\
& $0^{\circ}-15^{\circ}$ & \\
& $15^{\circ}-30^{\circ}$ & \\
Post-stack Seismic & $30^{\circ}-45^{\circ}$ & Full stack seismic data \\
\hline
\end{tabular}

towards identifying the prospective location. The estimation of petrophysical parameters is equally essential for the analysis of seismic inversion result.

Another major rock property for hydrocarbon identification is petrophysical property. All three wells (Study_R1, Study_ST1 and Study_B1) were used for estimating the petrophysical properties.

Post-stack seismic inversion (PSSI) was performed to transform the stacked seismic data into quantitative rock physics parameters with developed integrated earth model. Seismic inversion study changes the amplitude-based seismic data to acoustic impedance which helps in depicting the heterogeneity of the reservoir (Fig. 7). Acoustic impedance is a rock property and it gives more extensive structural and stratigraphy information. PSSI is mainly of four types namely, Constrained Sparse-Spike Inversion, Model-based inversion, Bandlimited impedance inversion, Coloured 


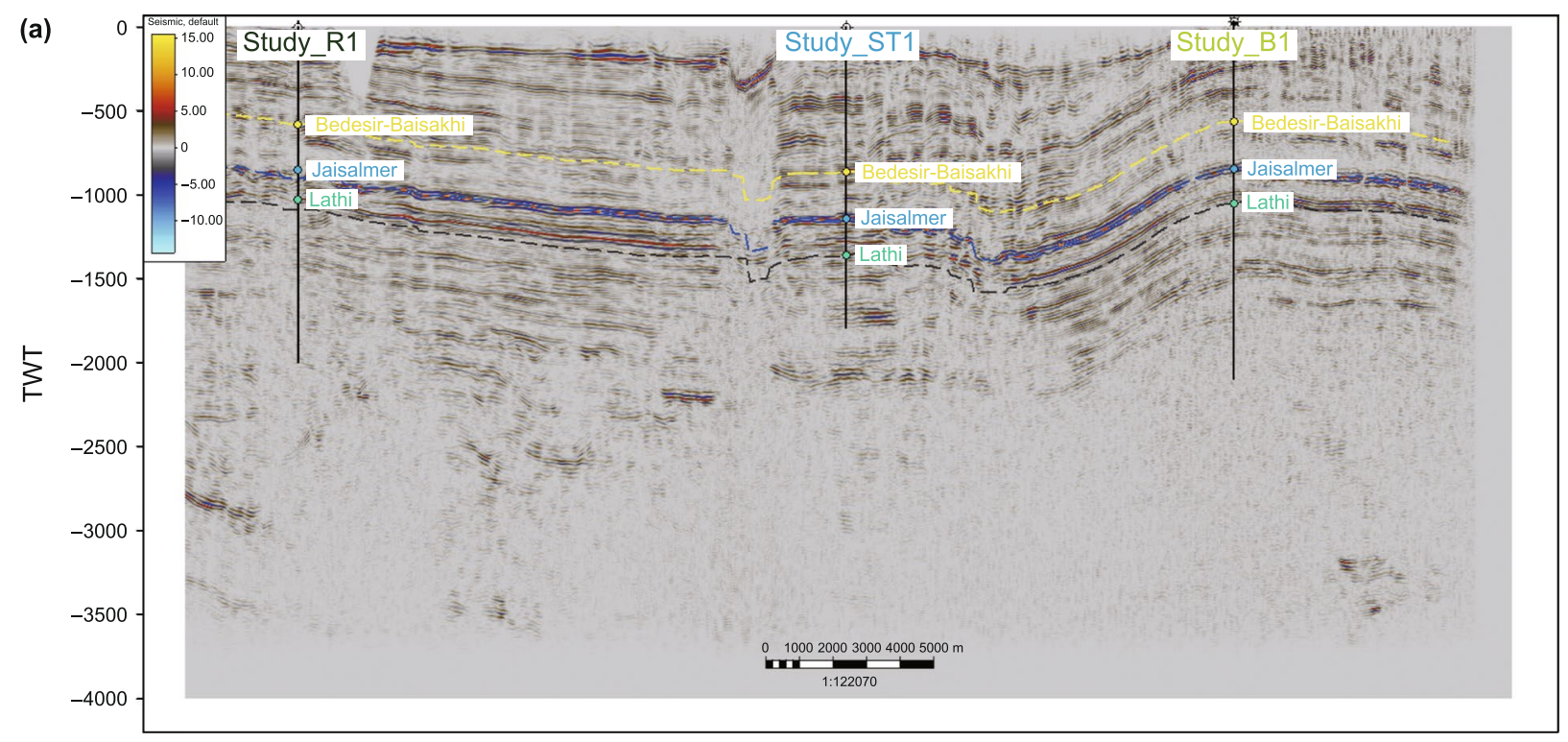

(b)

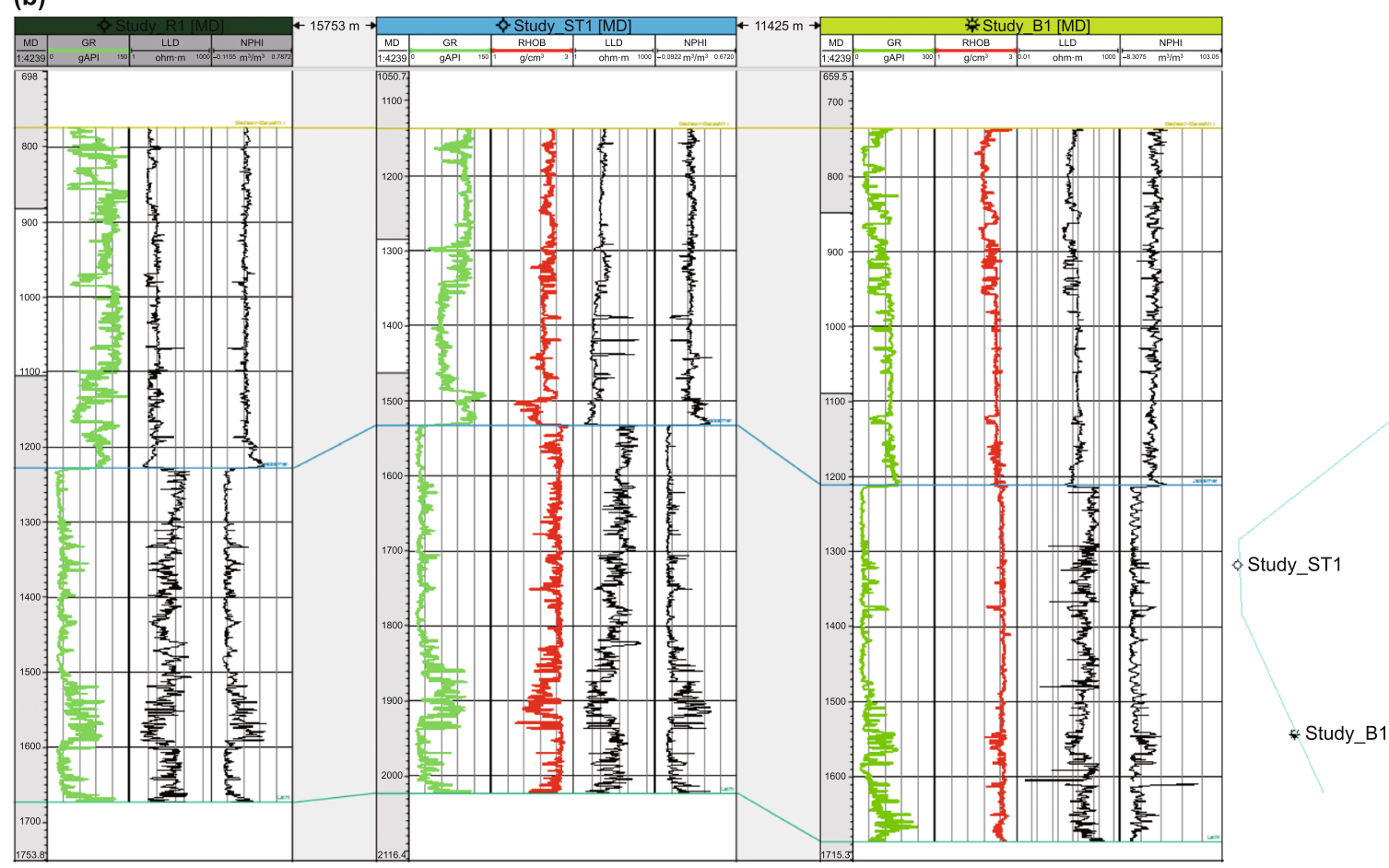

Fig. 7 The figure shows the overall sub-surface geological set-up of the tectonic and sedimentary part in the study region through post-stack seismic and conventional well log data; a interpreted post-stack seismic section has been represented through the study well; $\mathbf{b}$ well correlation has been represented in between study wells (Study_R1, Study_ST1 and Study_B1) with the help of conventional log data; to capture the structural variability below Bedesir-Baisakhi formation it has been flattened at well top level for each well

inversion (Maurya and Sarkar 2016). The seismic inverted volume has produced a high-resolution image of sub-surface geology and it does not suffer from the interference problem. The seismic inversion study was carried out based on the zero-phase wavelet to make the solution unique and to match the frequency and phase in between well and seismic data. Initially, the wavelet was estimated based on well to seismic tie in the study zone of a single study well (Study_R1). The final wavelet was estimated based on multi-well wavelet analysis of Study_R1, Study_ST1 and Study_B1 (Fig. 8). The estimated wavelet of each tie was compared for final wavelet selection. The well to seismic tie primarily concentrated in and around of the Jaisalmer formation as a major target of the study zone. 

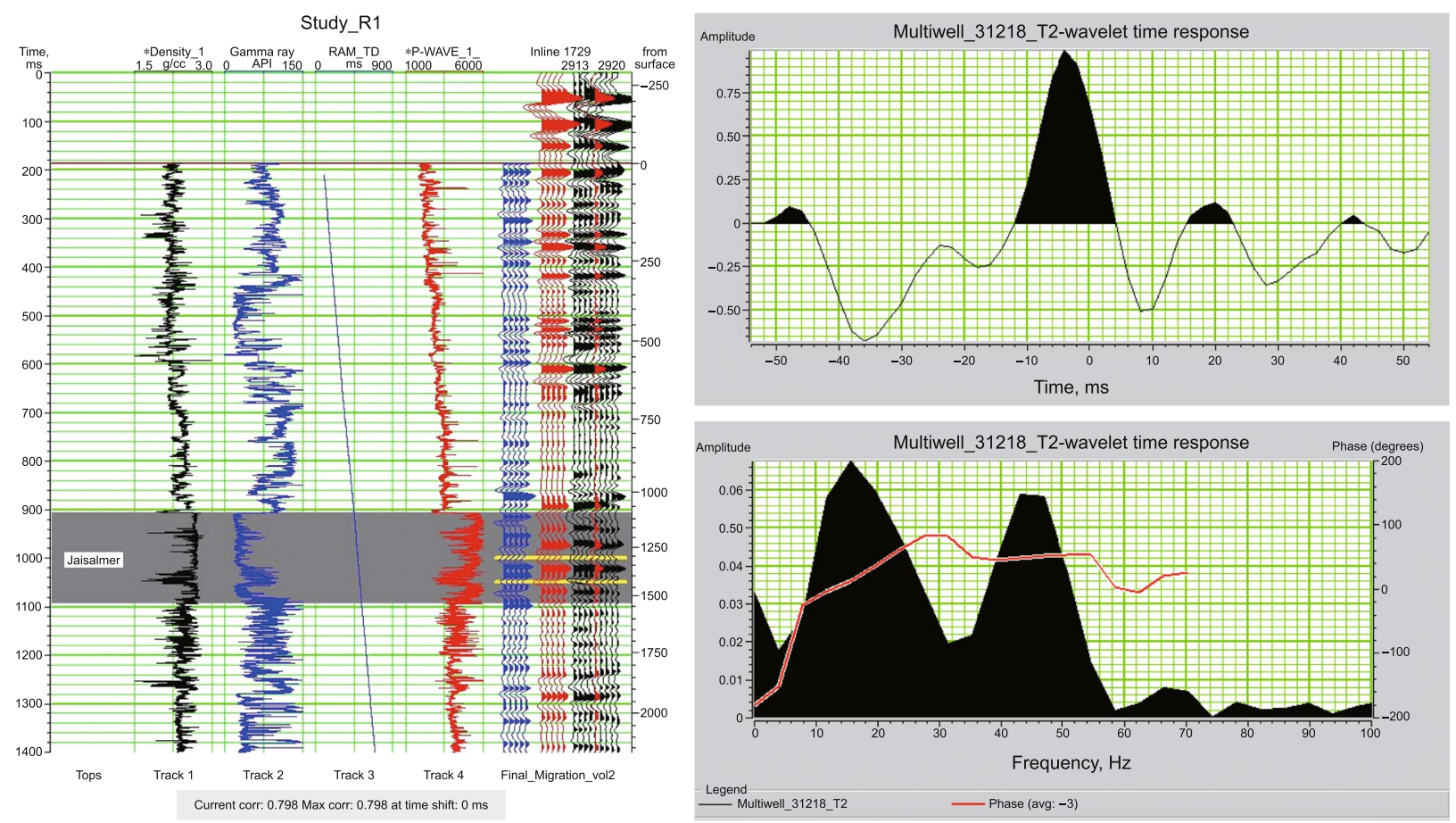

Fig. 8 The figure shows the well to seismic tie operation for generating time-depth relation and extraction; this is the example of the well Study_ R1, where Amplitude and Phase spectrum have been represented and 0.798 correlation coefficient has been achieved for the well Study_R1

PSSI is based on reflectivity equation and on one-dimensional convolution, i.e. $t=x * s$. P-impedance model can be calculated from the reflectivity equation but as a bandlimited wavelet eliminates the low-frequency component so to regain the low frequency an initial P-impedance model is generated from well log data. Supposing reflectivity to be 0.1 and using equation $M_{\mathrm{pj}}=\ln \left(Z_{\mathrm{p} j}\right)$, the reflectivity can be written as $S=1 / 2 D M_{\mathrm{p}}$ or in matrix shape:

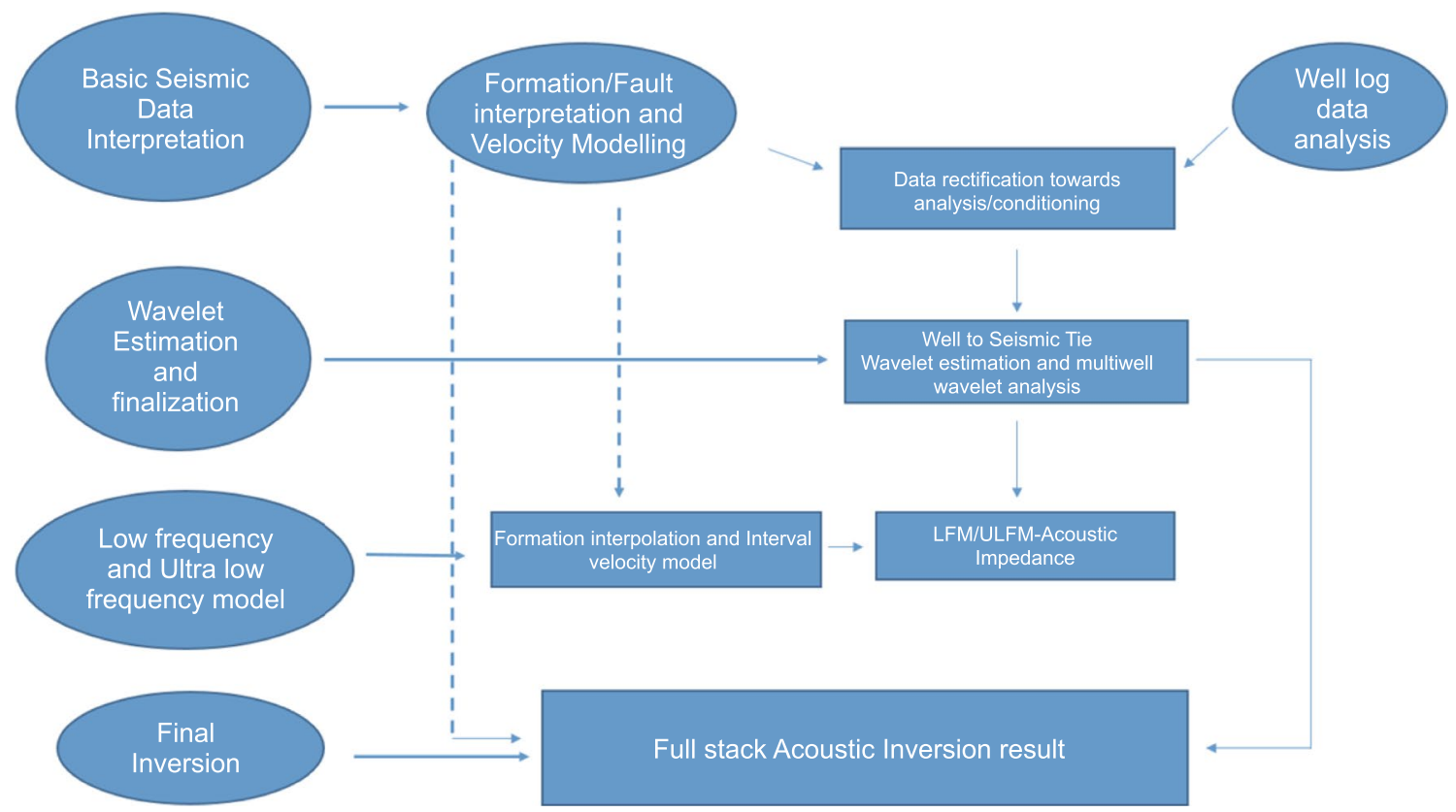

Fig. 9 Workflow for conducting post-stack seismic inversion 

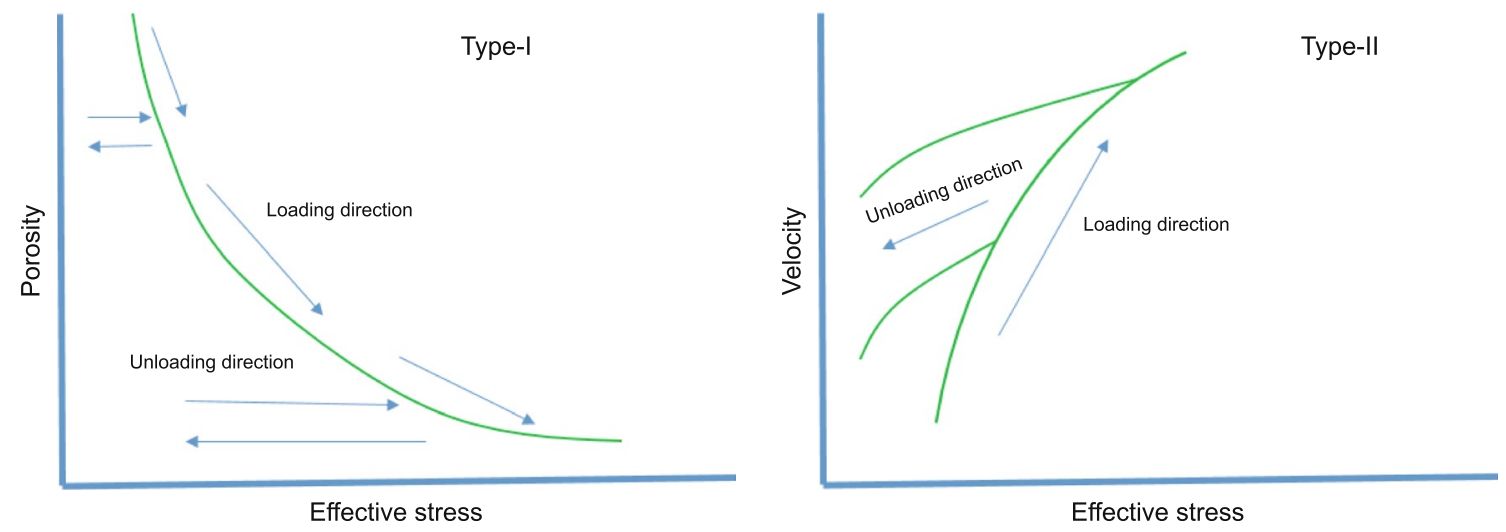

Fig. 10 The theoretical diagram shows the mechanism for the generation of overpressure for loading and unloading directional changes through variations of porosity and velocity with effective stress

$\left[\begin{array}{c}s_{\mathrm{p} 1} \\ s_{\mathrm{p} 2} \\ \vdots \\ s_{\mathrm{p} N}\end{array}\right]=\frac{1}{2}\left[\begin{array}{cccc}-1 & 1 & 0 & \cdots \\ 0 & -1 & 1 & \ddots \\ 0 & 0 & -1 & \ddots \\ \vdots & \ddots & \ddots & \ddots\end{array}\right]\left[\begin{array}{c}M_{p 1} \\ M_{p 2} \\ \vdots \\ M_{p N}\end{array}\right]$

1-D convolution model, $t=x * s$ can also be written in matrix shape as:

$\left[\begin{array}{c}t_{1} \\ t_{2} \\ \vdots \\ t_{N}\end{array}\right]=\left[\begin{array}{cccc}X_{1} & 0 & 0 & \cdots \\ X_{2} & X_{1} & 0 & \ddots \\ X_{3} & X_{2} & X_{1} & \ddots \\ \vdots & \ddots & \ddots & \ddots\end{array}\right]\left[\begin{array}{c}s_{\mathrm{p} 1} \\ s_{\mathrm{p} 2} \\ \vdots \\ s_{\mathrm{p} N}\end{array}\right]$

Combining of the equations for post-stack inversion is represented as:

$T=1 / 2 X D M_{\mathrm{p}}$

where $T$ is stacked seismic trace, $X$ is wavelet matrix in (13), $D$ is the derivative matrix in (12) and $M_{\mathrm{p}}$ is the natural logarithm of P-impedance.

Initially, we have used the initial impedance model and with the information of seismic trace and extracted seismic wavelet, $M_{\mathrm{p}}$ is estimated using standard matrix inversion (Moosavi and Mokhtari 2016).

We have used the following workflow (Fig. 9) to conducting model-based post-stack seismic inversion.

\section{Result and discussion}

The study was taken up to establish the chances of success for hydrocarbon exploration in the study area. Structural complexity has been observed in the study area. Frequent changes of structural set-up in the sub-surface geology make it difficult in successful exploration. Analogue study of nearby areas shows the maturity of the petroleum system. We have seen the encouraging result for hydrocarbon

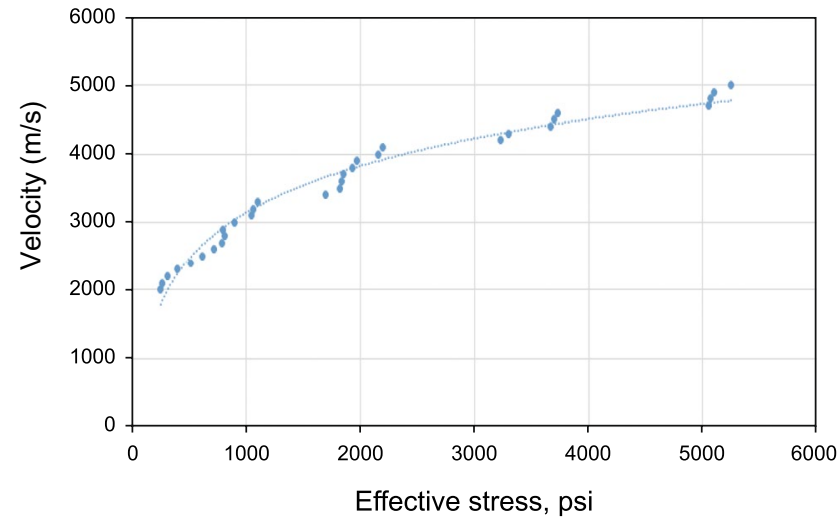

Fig. 11 Variation of estimated effective stress with the P-wave velocity has been presented here to characterize the loading and unloading system in the well Study_R1

exploration in rock property and petrophysical property for a tight reservoir in the study area. In this case, geomechanical properties such as pore pressure and fracture pressure can play a vital role in capturing the reason behind unsuccess.

We have estimated both pore and fracture pressure from well data in the current work. This estimation shows a good relationship with seismic inversion based result. The study results show different level of correlation at well position. The well level correlation has been developed based on acoustic impedance vs pore pressure and fracture pressure. Well correlation between acoustic impedance and pressure (pore and fracture) shows a distinct separation between preand post-Jurassic age. Bedesir-Baisakhi formation comes under the Cretaceous age (pre-Jurassic), whereas the Jaisalmer formation considers in the Jurassic age (post-Jurassic). Here, the Jaisalmer limestone formation acts as a regional marker for separating two different depositional units such as clastic and carbonate. Other than depth porosity and velocity both are related to effective stress. It has been observed that sometimes porosity is not decreasing with depth due 

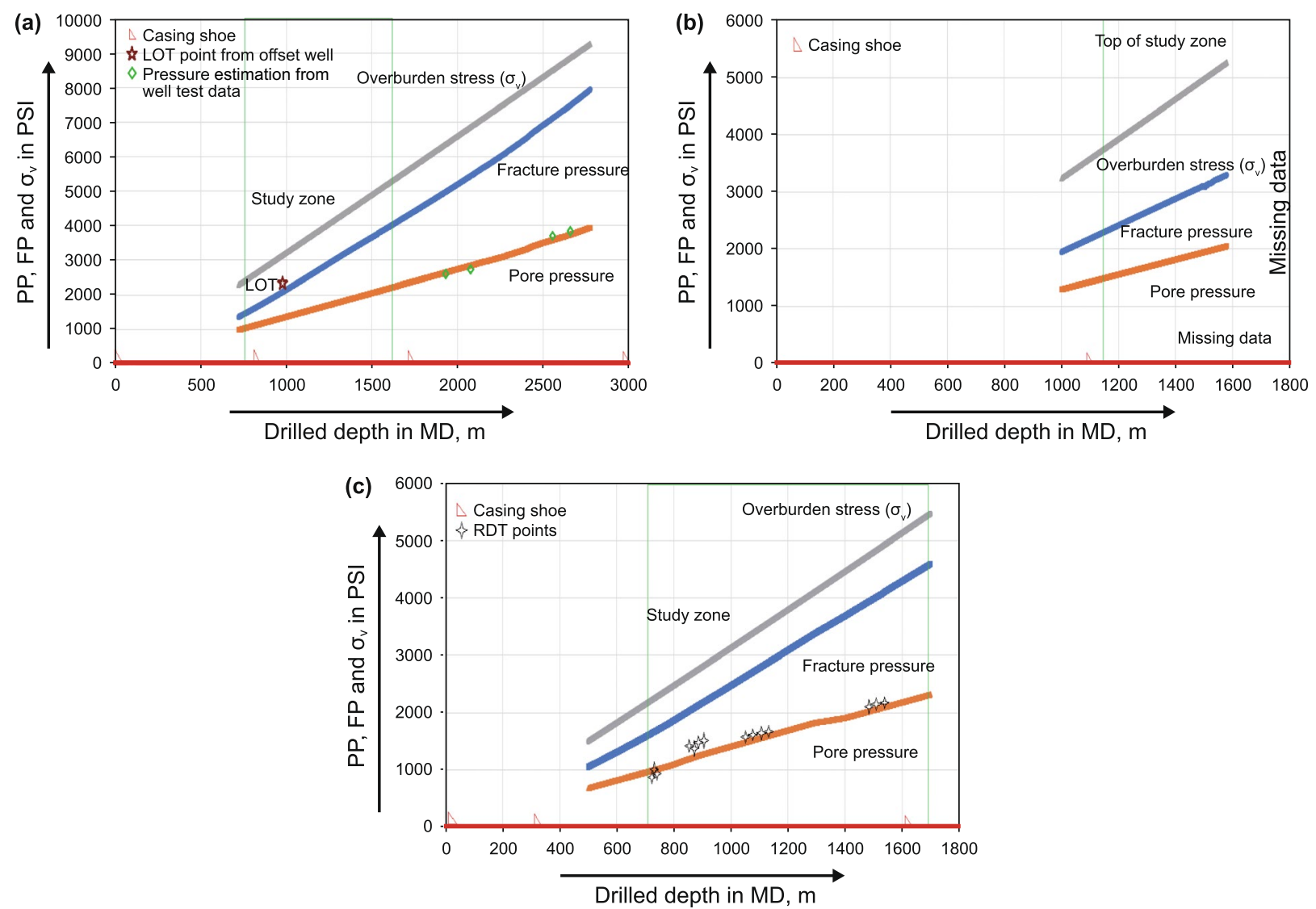

Fig. 12 The figure shows the variations of different pressures (pore pressure, fracture pressure and overburden stress) with depth in the study zone; a variations of pressures (pore pressure, fracture pressure and overburden stress) with depth has been represented for the well Study_R1 for whole study zone; LOT data have been draped over estimated fracture pressure data and the pore pressure from the well test result has been mentioned over the estimated pore pressure data; $\mathbf{b}$ variations of pressures (pore pressure, fracture pressure and overburden stress) with depth has been represented for the well Study_ST1 for Bedesir-Baisakhi zone as required data was limited; c variations of pressures (pore pressure, fracture pressure and overburden stress) with depth has been represented for the well Study_B1 for whole study zone; RDT data have been draped over estimated pore pressure data

to small increment of effective stress with depth in respect to normal compaction scenarios. A relation between compressional velocity and effective stress has been observed which shows that increment of compressional velocity with effective stress.

Figure 10 shows the overpressure mechanism, which shows the variation of velocity and porosity with effective stress. Generally, it observes two types of procedures for the overpressure mechanism. The first one is related to the variation of porosity with a fast depositional activity which considers as under-compaction and overpressure mechanism is related to the loading of sediments. The second type of overpressure mechanism is related to the variation of velocity instead of porosity, and it is mostly related to the repeated acts of pressure mechanism on the zone. This kind of activity usually observes during the unloading of sediments. Current interpretation suggests that the overpressure mechanism of this area is related to the first one which related to the loading of sediments. We have found a supply of sediments with different grain size with geological age. Distinct changes of pore pressure at the interface of the Bedesir-Baisakhi and the Jaisalmer formation support the analogy of type one overpressure mechanism through the influx of sediments in the study zone. A composite plot of between compressional velocity and effective stress (Fig. 11) shows the type one overpressure mechanism at well level in the study area.

Eaton's method was used to estimate the pore and fracture pressure (Dasgupta et al. 2016) for all three wells (Study R1, Study_ST1 and Study_B1). NCTL was evaluated for the establishment of generalized normal compaction trend. Conditioning of well data was an essential step for this study. Good quality data were accumulated from the well Study_R1 and Study_B1; however, moderate data quality was observed in the well Study_ST1 data. The moderate quality of data of the well Study_ST1 has been observed after conditioning 

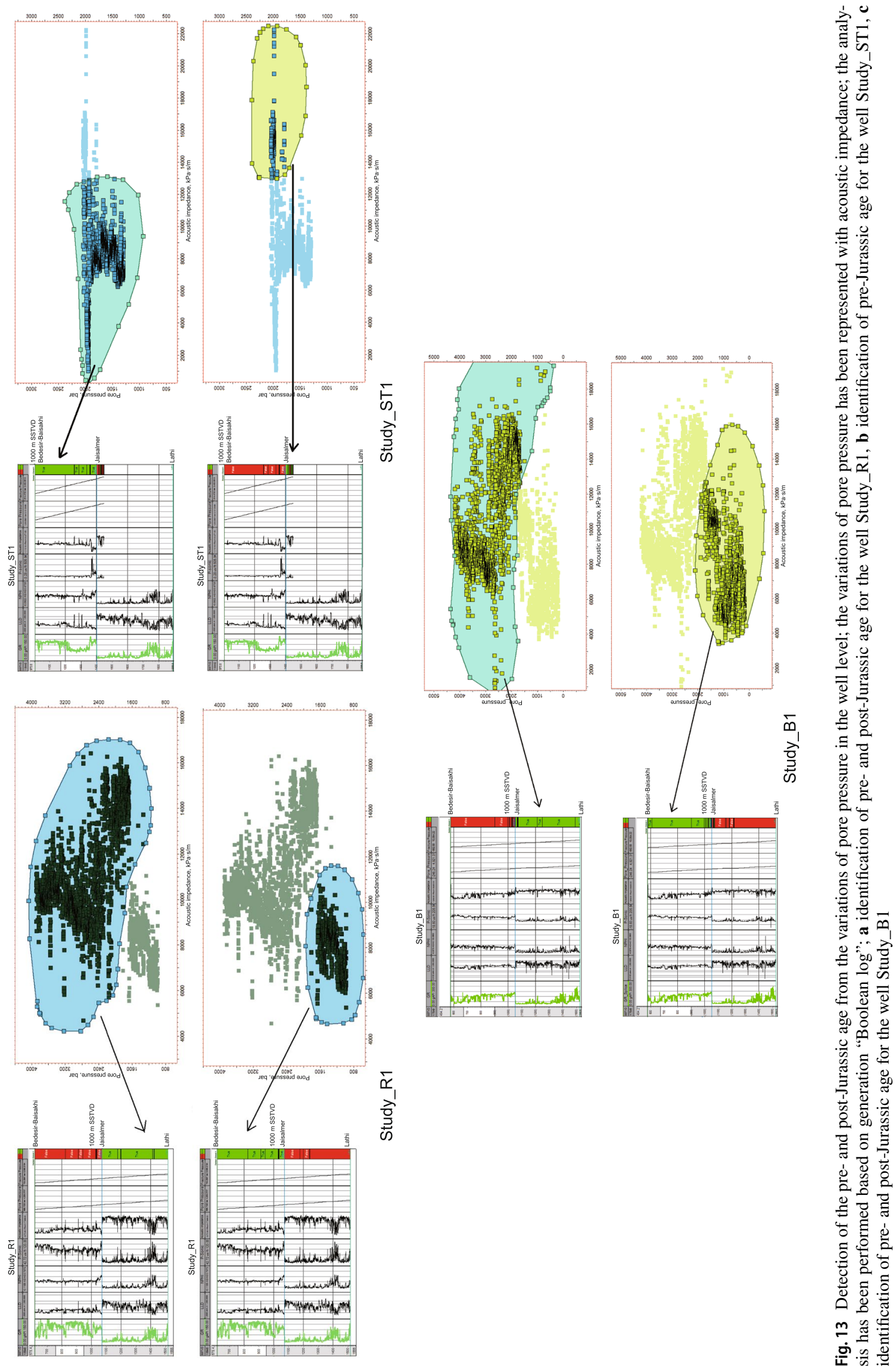

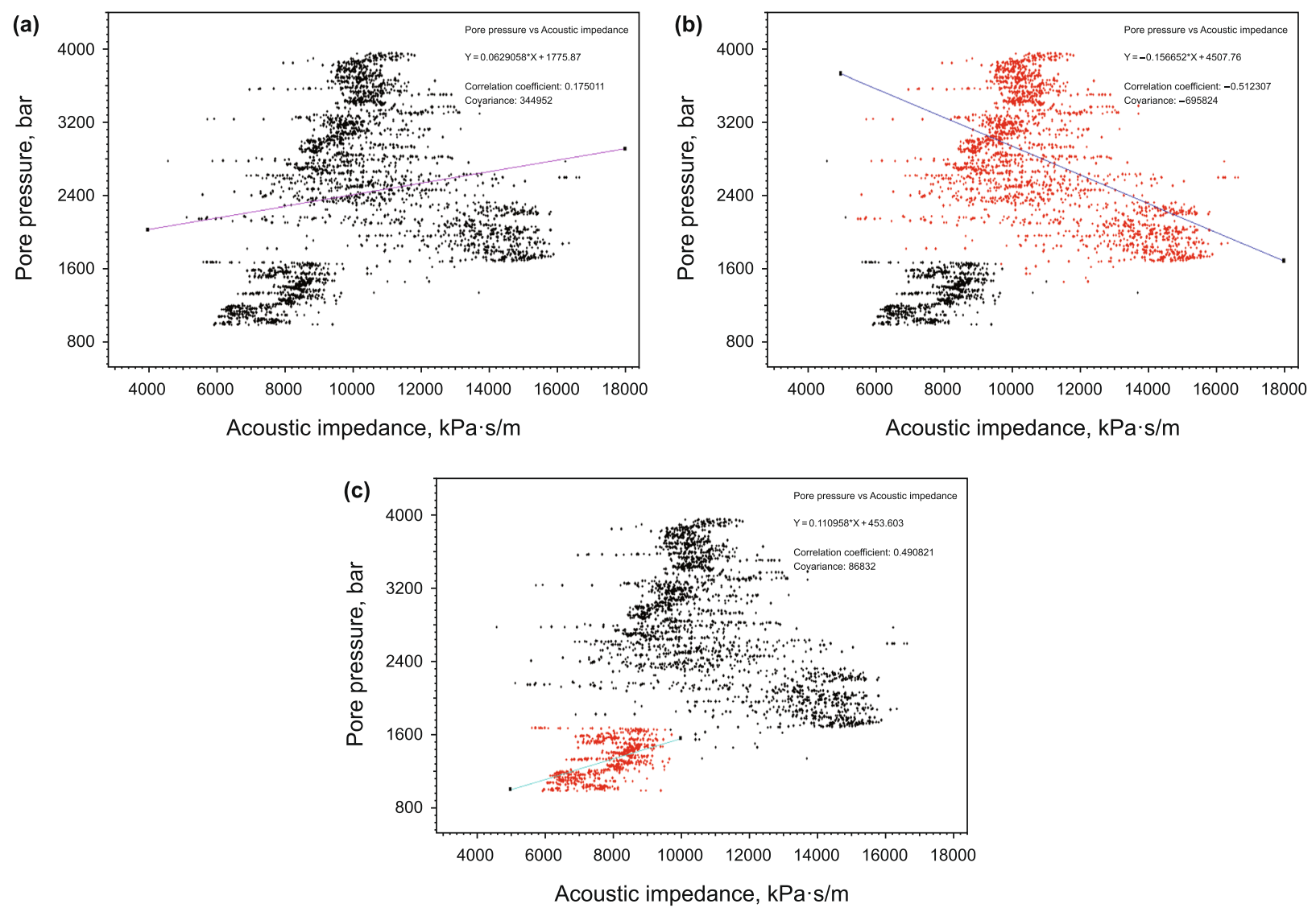

Fig. 14 Pore pressure variations have been expressed with acoustic impedance in the well Study_R1; a this is for whole study zone (BedesirBaisakhi to Jaisalmer formation), b this figure shows for post-Jurassic age (Jaisalmer formation), $\mathbf{c}$ this plot shows for pre-Jurassic age (BedesirBaisakhi formation)

of well $\log$ data in the well. Figure 12 shows a significant result of this current study where variations of pore pressure, fracture pressure and overburden stress was captured with depth in the study zone. The result shows that the estimated pore pressure and fracture pressure are very close to direct measurement. Well test results of Study_R1 well show the similarity with estimated pore pressure. LOT data of offset well are similar to estimated fracture pressure of Study_R1 well, and RDT results are almost identical to the estimated pore pressure of Study_B1. The pressure variation in a few parts of the study zone was not captured in Study_ST1 due to unavailability of data.

Optimized cut-off values were used over GR (gamma-ray) log data for lithology classification where major lithologies are identified as sandstone, limestone and shale. However, current analysis shows the significant presence of sandstone and limestone in clastic and carbonate sequence. Based on pore pressure and fracture pressure analysis depositional sequences were separated. Figure 13 shows the separation of the sequences of pre- and post-Jurassic age based on pore pressure variations of all three study wells. We have seen apart from Study_ST1 (due to limited data), other two wells have separated the sequences notably based on pore pressure. However, for Study_ST1 well pre-Jurassic age was identified significantly and minor part was identified in postJurassic sequences. Correlation between acoustic impedance and pressures(pore and fracture) for the full depositional unit (the Bedesir-Baisakhi and the Jaisalmer) of the study zone shows low correlation coefficient. The same correlation shows a higher value when a single depositional unit (the Bedesir-Baisakhi or the Jaisalmer) is considered.

The estimated pore pressure for the well Study_R1 was correlated with estimated acoustic impedance which has produced a correlation coefficient of 0.17 for full study zone, 

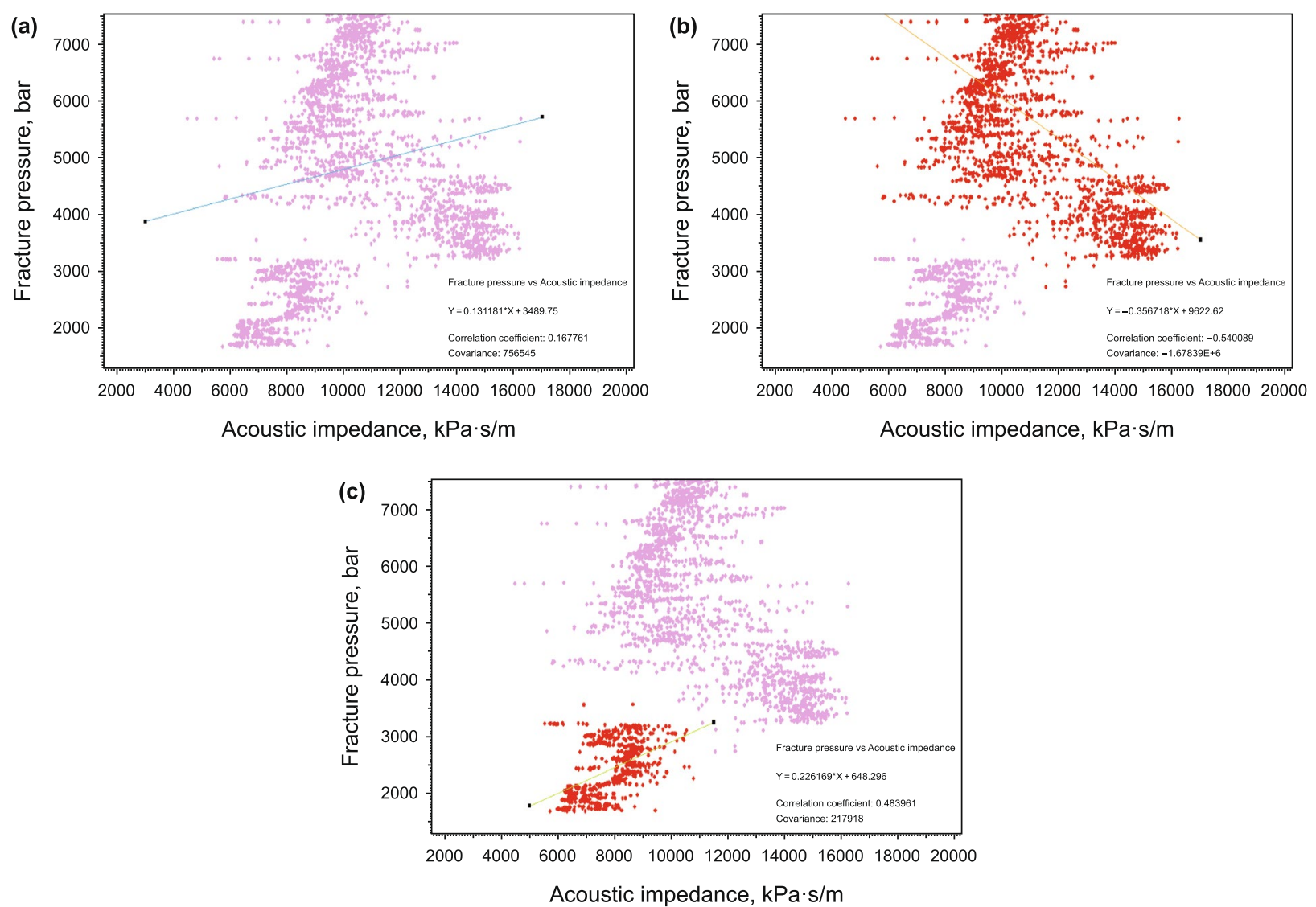

Fig. 15 Fracture pressure variations have been expressed with acoustic impedance in the well Study_R1; $\mathbf{a}$ this is for whole study zone (BedesirBaisakhi to Jaisalmer formation), b this figure shows for post-Jurassic age (Jaisalmer formation), $\mathbf{c}$ this plot shows for pre-Jurassic age (BedesirBaisakhi formation)

-0.512 (negative regression) for post-Jurassic age (the Jaisalmer formation) and 0.49 for pre-Jurassic age (the BedesirBaisakhi formation) (Fig. 14). The same analysis was performed (Fig. 15) for fracture pressure of the well Study_R1 where we got a correlation coefficient for full study zone, the Jaisalmer and the Bedesir-Baisakhi formation as 0.16, -0.54 (negative regression) and 0.48 , respectively.

The analysis shows a good agreement in mixed clastic and carbonate sequences.

Study_B1 well produced a correlation coefficient of 0.20 , -0.51 (negative regression) and 0.13 between pore pressure and acoustic impedance for full study zone, the Jaisalmer and the Bedesir-Baisakhi formation (Fig. 16). The study shows a low correlation for Bedesir-Baisakhi formation due to the presence of high aperture fractures in the study zone. The pressure profile was unable to maintain a certain trend in the study zone due to the presence of fractures. Figure 17 shows the variation of estimated fracture pressure with the estimated acoustic impedance of the well Study_B1. Here, we have got a correlation coefficient of 0.49 for the full zone of study, whereas 0.71 was achieved in pre-Jurassic deposition and for post-Jurassic, it was -0.48 (negative regression).

Study_ST1 well was drilled near faulting zone where complex heterogeneity in sub-surface formation is observed. The required well log dataset was not available for full zone of study in this well. To avoid the biases in the results, we conducted the pore and fracture pressure analysis in the Bedesir-Baisakhi formation only. However, few well $\log$ points are observed for required dataset in the top part of the Jaisalmer formation. But these points were badly affected and proper correlation was not observed. 

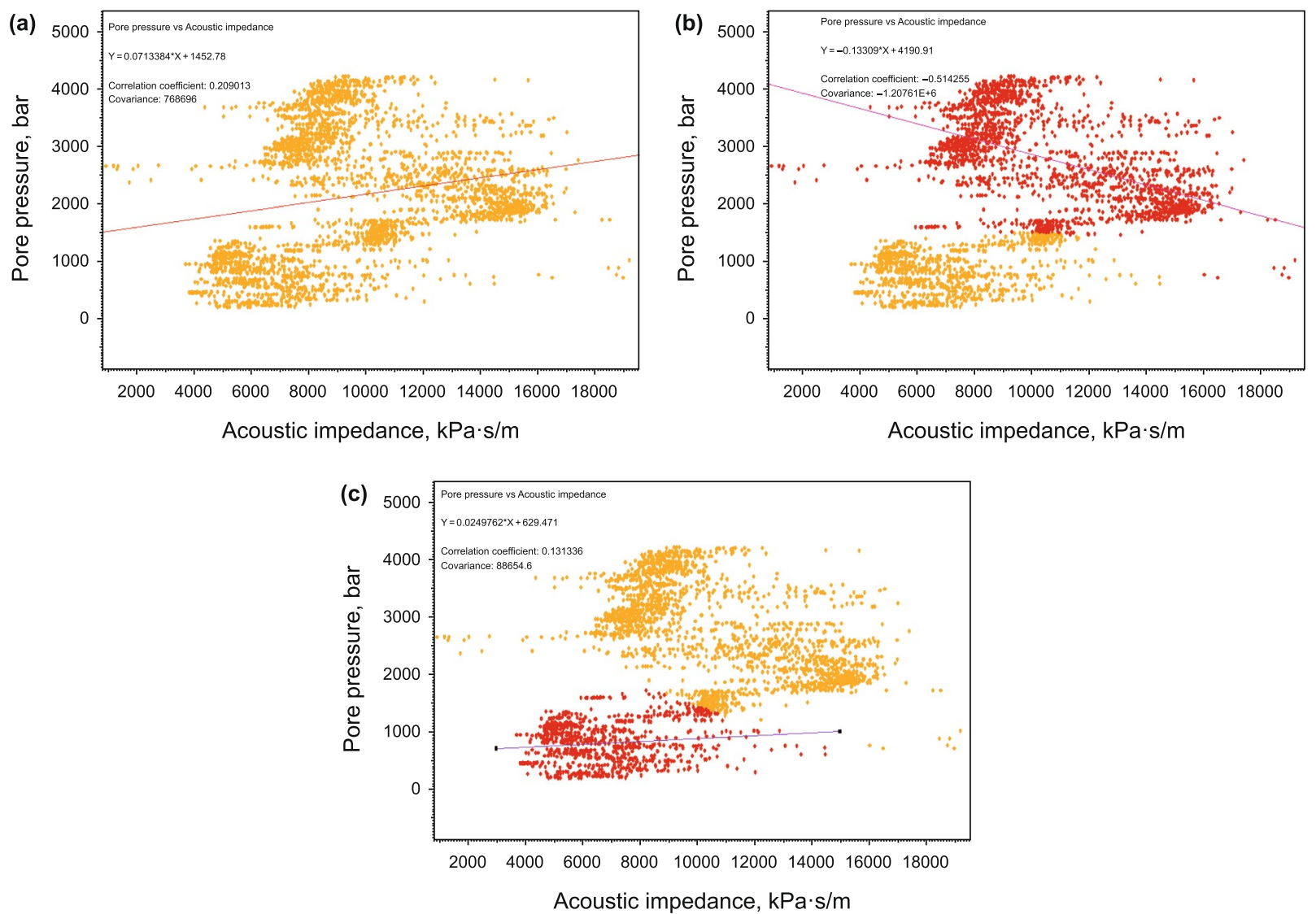

Fig. 16 Pore pressure variations have been expressed with acoustic impedance in the well Study_B1, a this is for whole study zone (BedesirBaisakhi to Jaisalmer formation), b this figure shows for post-Jurassic age (Jaisalmer formation), $\mathbf{c}$ this plot shows for pre-Jurassic age (BedesirBaisakhi formation)

The probable reason for changes in log character due to complex geological set-up and sudden changes from clastic to carbonate rock composition. During generating of correlation between pressure (pore and fracture) with acoustic impedance these points considered as outliers in the well Study_ST1. Pore and fracture pressure for preJurassic age have produced 0.38 and 0.28 correlation coefficient with acoustic impedance in this well (Fig. 18).

The spatial estimation of pore pressure was carried out through post-stack seismic inversion analysis. This inversion study was conducted to capture the structural and lithological changes away from the well. To get the knowledge of pore pressure of pre-drill well this analysis was mandatory. Data quality and limitation has inspired us to focus on a few major components in the seismic inversion which supplied significant information in the latter stage of this study on changes of pore pressure in this area. The workflow mentioned above (chart diagram) is showing one significant aspect for seismic inversion study. In this workflow, we could observe the presence of LFM and ULFM (Datta Gupta et al. 2012).

Developing of a robust LFM and ULFM was a challenging job in this study area. The LFM and ULFM have captured the subtle changes of sub-surface geology. To prepare these models, we have used conditioned seismic interval velocity (Fig. 19) which was integrated with well velocity. This integrated velocity model was used for converting seismic impedance volume from the time domain to the depth domain. The P-impedance volume in depth domain was used to capture the pressure variation in the BedesirBaisakhi and the Jaisalmer formation. Figure 20 shows the lithological and structural changes in between three study wells (Study_R1, Study_ST1 and Study_B1) through depth converted P-impedance volume. The acoustic impedance log 


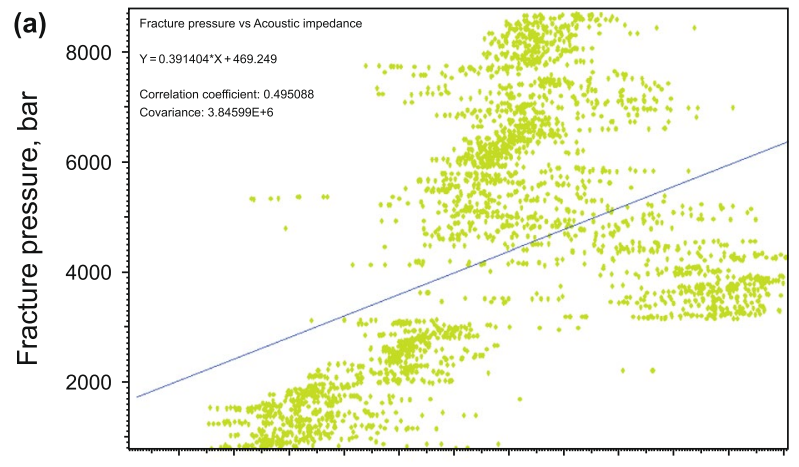

$4000 \quad 5000 \quad 6000700080009000100001100012000130001400015000$

Acoustic impedance, $\mathrm{kPa} \cdot \mathrm{s} / \mathrm{m}$

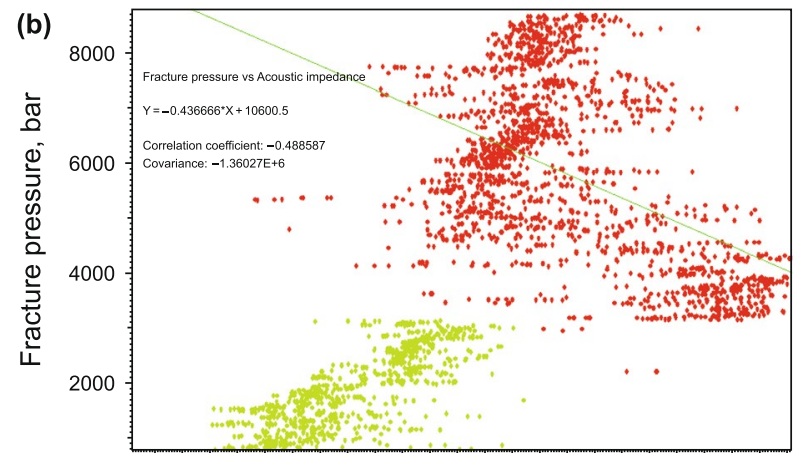

$4000 \quad 5000 \quad 6000700080009000100001100012000130001400015000$

Acoustic impedance, $\mathrm{kPa} \cdot \mathrm{s} / \mathrm{m}$

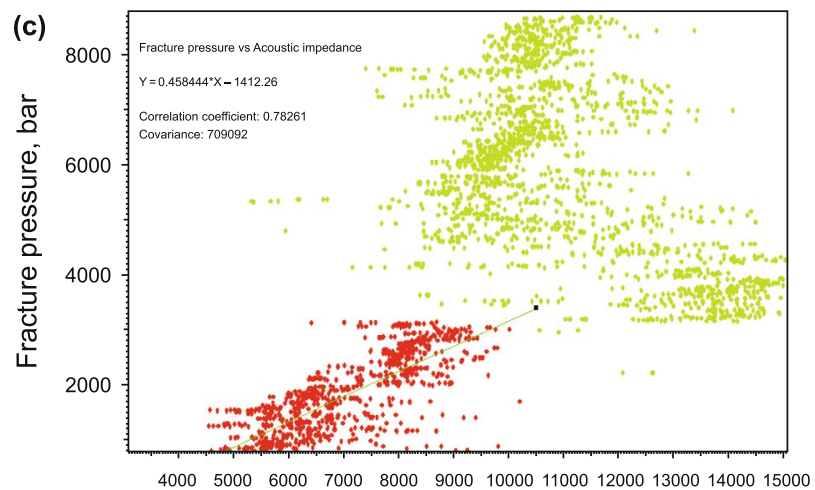

Acoustic impedance, $\mathrm{kPa} \cdot \mathrm{s} / \mathrm{m}$

Fig. 17 Fracture pressure variations have been expressed with acoustic impedance in the well Study_B1; a this is for whole study zone (BedesirBaisakhi to Jaisalmer formation), b this figure shows for post-Jurassic age (Jaisalmer formation), $\mathbf{c}$ this plot shows for pre-Jurassic age (BedesirBaisakhi formation)

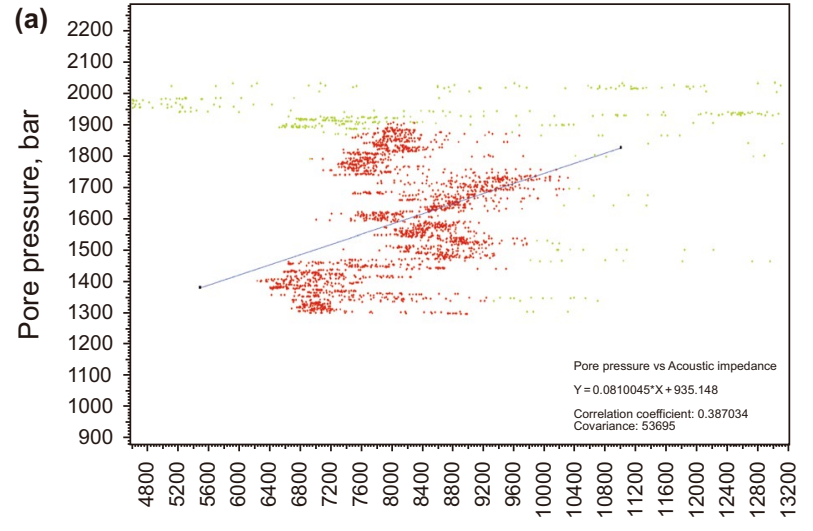

Acoustic impedance, $\mathrm{kPa} \cdot \mathrm{s} / \mathrm{m}$

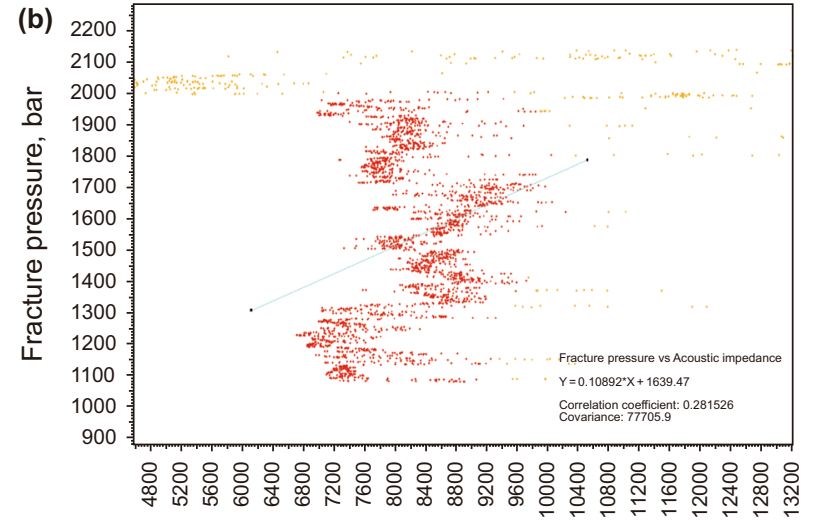

Acoustic impedance, $\mathrm{kPa} \cdot \mathrm{s} / \mathrm{m}$

Fig. 18 Pore and fracture pressure variations have been expressed with acoustic impedance in the well Study_ST1, a this figure shows pore pressure variations for the pre-Jurassic zone (Bedesir-Baisakhi), b his figure shows fracture pressure variations for the pre-Jurassic zone (BedesirBaisakhi) 


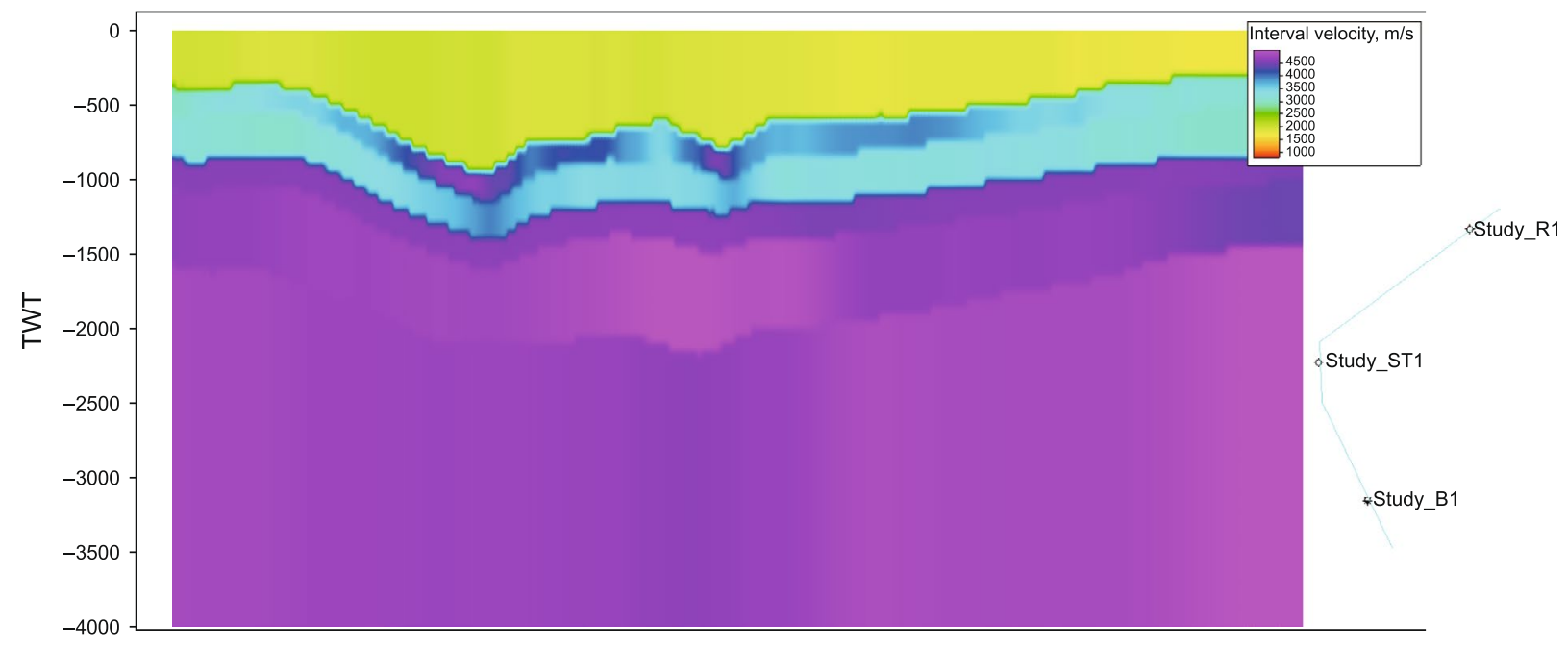

Fig. 19 Integrated velocity model with the help of seismic and well log velocity; the model has been focussed in the ULFM and LFM part; the velocity model was used for post-stack inversion process and related pressure estimation purposes

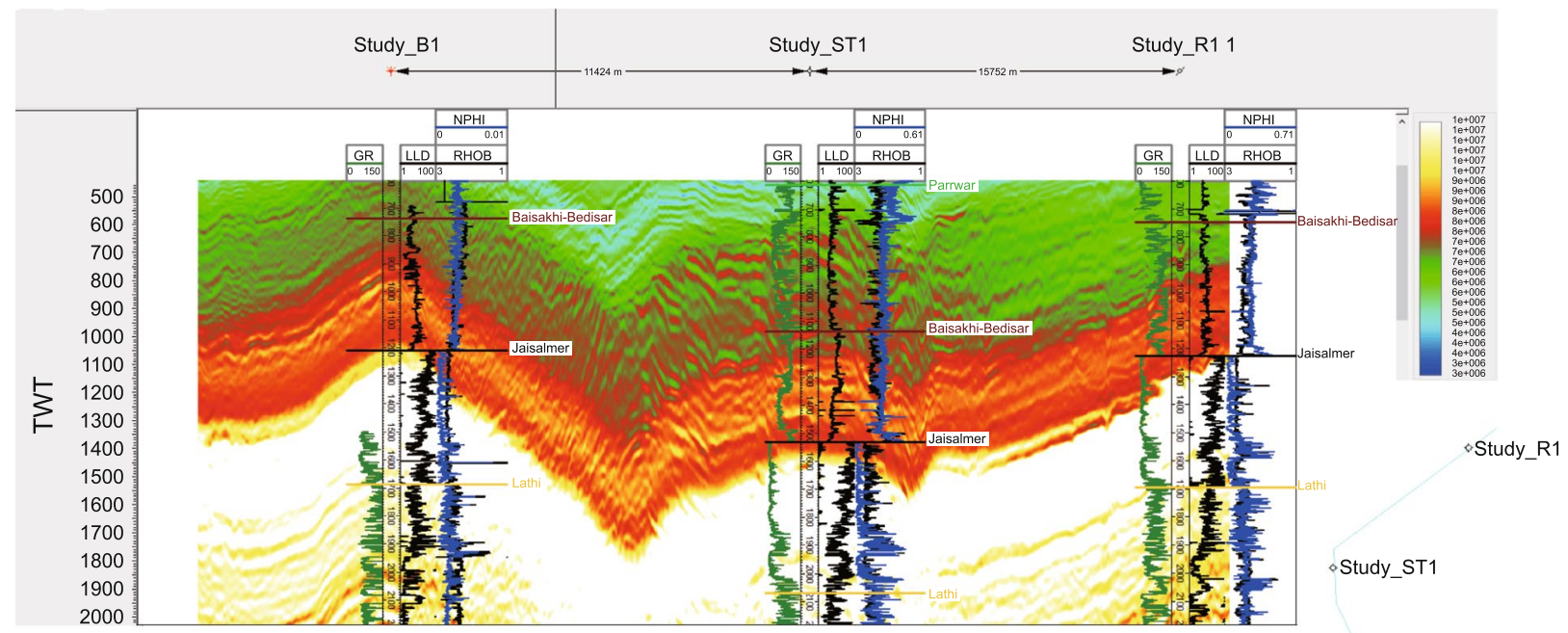

*Study_B1

Fig. 20 The outcome of the post-stack inversion process passed through study wells (Study_R1, Study_ST1 and Study_B1) has been represented; the conventional well log data have been placed over the inverted section to capture the structural and sedimentary changes in the study zone

was extracted as a property log from depth converted acoustic impedance volume along the well path of three study wells (Chatterjee et al. 2013). This log was extracted due to comparative analysis with well based outcome. Figure 21 shows a correlation between the study wells where we have observed unique lithological variation with depositional variety based on the inverted result and GR (gamma-ray) $\log$.
Cumulative pressures (pore and fracture) were plotted with acoustic impedance for both pre- and post-Jurassic age. The idea was to capture the pore and fracture pressure variation within a $27.176 \mathrm{~km}$ span $(15.752 \mathrm{~km}$ between Study_ST1 and Study_R1; 11.424 km between Study_ST1 and Study_B1) based on the post-stack seismic inverted study. This part of the study shows the significance of pore and fracture pressure estimation for away from well 


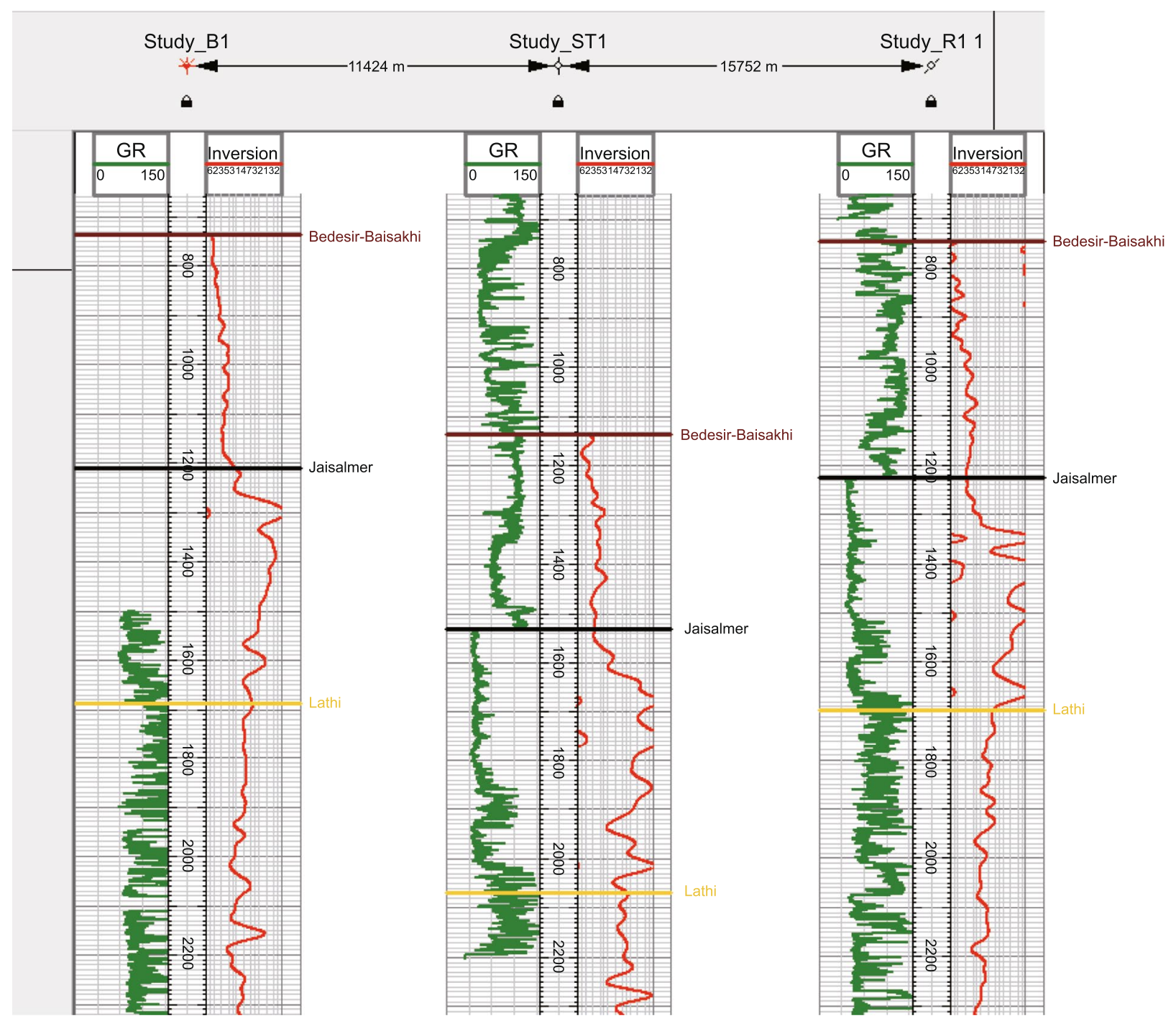

Fig. 21 The lithological variations have been represented with the help of GR (gamma-ray) well log of study wells (Study_R1, Study_ST1 and Study_B1) and extracted acoustic impedance log from post-stack inverted seismic volume

location through the integration of inversion study. Both pressure data were resampled at seismic frequency before plotting. Since Study_ST1 well was drilled near faulted region hence limitation of cross-correlation was observed for both correlation of pore and fracture pressure with acoustic impedance. Figure 22 shows the correlation of pore and fracture pressure with acoustic impedance for pre- and post-Jurassic age; however, for post-Jurassic age well Study_ST1 was not considered due to limited dataset. We have established a good correlation for both ages and separate trend lines (pre-Jurassic-positive regression trend and post-Jurassic-negative regression trend) are also observed from this correlation. One well has been proposed after the proper measurement of pore pressure of the study zone. The other properties of reservoir rock such as rock physical and petrophysical were considered favourable for hydrocarbon exploration based on nearby discoveries. The challenge was to capture the sudden changes of pore and fracture pressure in the study zone before proposing a new location for drilling. Estimation of pressures (pore and fracture) was carried out based on NCTL, seismic inversion study and integrated velocity. The required well log data, tops and other necessary parameters for calculating the pore and fracture pressure 

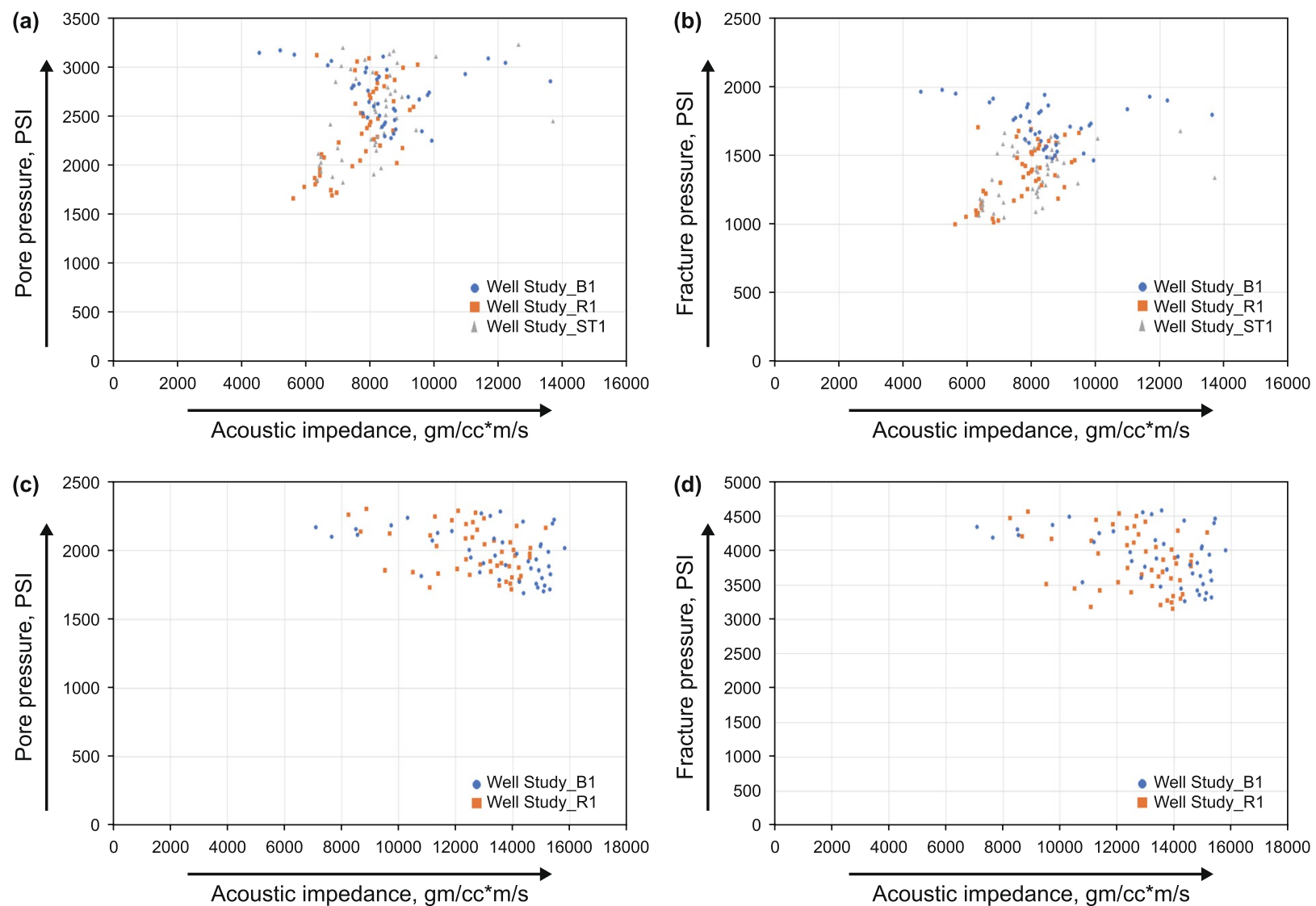

Fig. 22 Variations of pore and fracture pressure with extracted acoustic impedance log have been captured for all study wells for pre- and postJurassic age; a variations of pore pressure with extracted acoustic impedance log in all study wells for pre-Jurassic age, $\mathbf{b}$ variations of fracture pressure with extracted acoustic impedance log in all study wells for pre-Jurassic age, $\mathbf{c}$ variations of pore pressure with extracted acoustic impedance log in the wells Study_R1 and Study_B1 for post-Jurassic age, d variations of fracture pressure with extracted acoustic impedance log in the wells Study_R1 and Study_B1 for post-Jurassic age

of the proposed well were estimated based on robust interpolation algorithm and analogue data supported by nearby drilled wells. Figure 23 shows the pressure variation of the newly proposed well for both geological ages (preand post-Jurassic age). Based on this study one optimized location (Fig. 24) has been finalized for further drilling.

\section{Conclusion}

We have reached to following conclusions after completing this study.

1. Seismic inversion produces a layer property of sub-surface geology. The pore pressure and fracture pressure estimation from the outcome of seismic inversion study which produce precise results for a heterogeneous and tectonically active reservoir.
2. To capture the small aperture fractures from the seismic signature, analysis of the low-frequency and ultra-low frequency spectrum is essential. Seismic inversion can capture the low-frequency components of all thresholds. The pore and fracture pressure changes along fault and fractures were analysed precisely from post-stack seismic inverted data in this study.

3. Both pore and fracture pressure estimation is directly linked with velocity function. The robust interval velocity model, which was a part of the seismic inversion process and it has produced a finer level of pore pressure estimation. The pressure estimation from all three study wells_-Study_R1, Study_ST1 and Study_B1 has shown good correlation with interval velocity based estimation. Changes in the correlation are reflected in the structurally complex areas.

4. Distinctly pre- and post-Jurassic age has been separated by pore and fracture pressure variation. This variation 


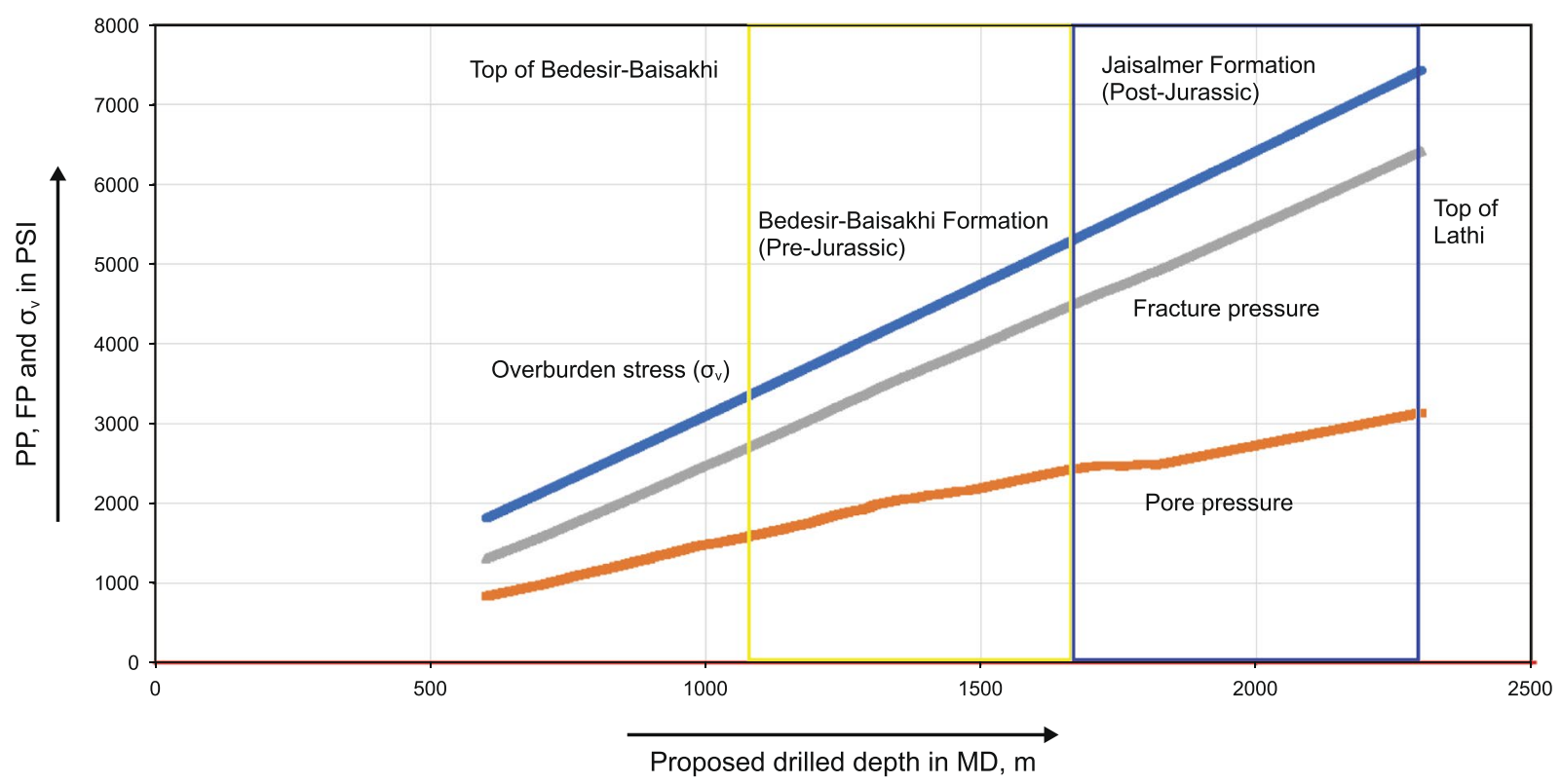

Fig. 23 The figure shows the variations of different pressures (pore pressure, fracture pressure and overburden stress) with depth in the study zone (Bedesir-Baisakhi and Jaisalmer formation) for newly proposed well location
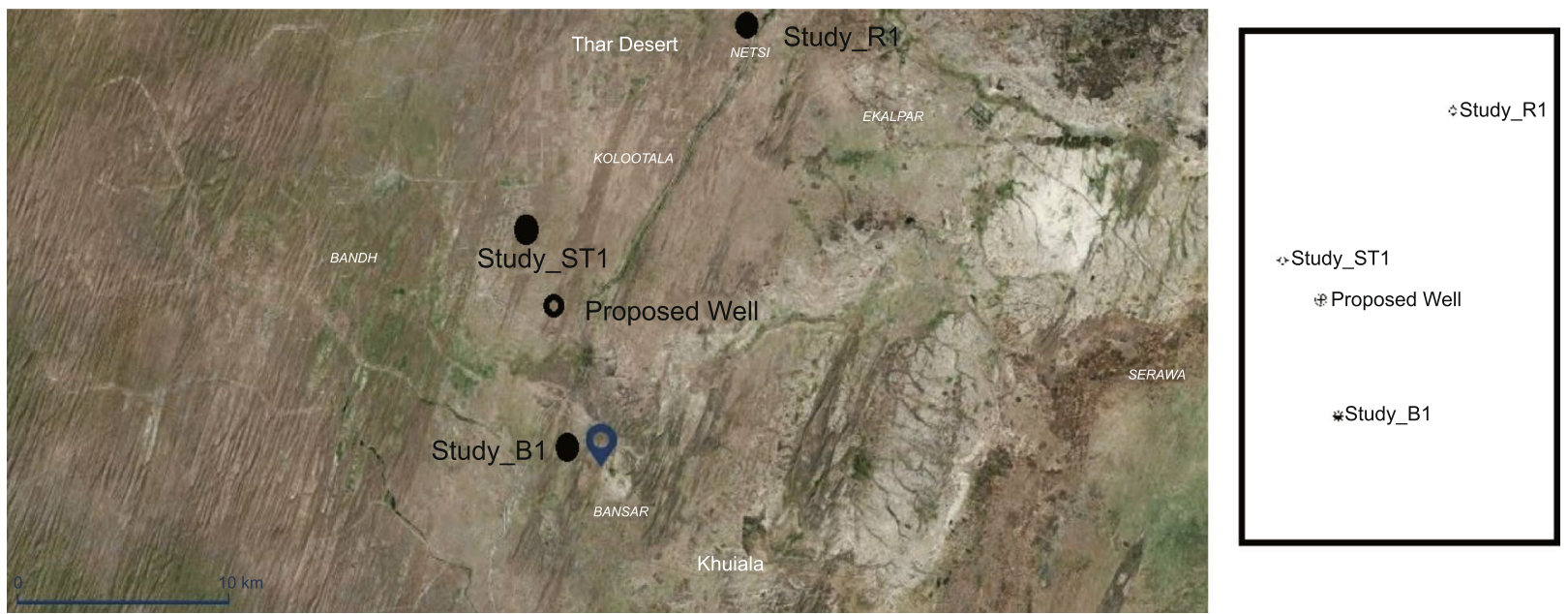

Fig. 24 Outcrop and geographical position of newly proposed well based on the current study

shows the different nature of hydrocarbon-bearing reservoir rock such as clastic and carbonate rock in different pressure regime.

5. The study has produced as a full-scale analytical workflow for pre and post drill pressure analysis based on well and seismic data. The study has shown a good calibration between the estimated results and field acquired results such as LOT, well test and RDT result. Based on this study one drillable location has been proposed after measuring the pore and fracture pressure of the reservoir.

6. This study will be useful where sub-surface geology is complex and changes of depositional sequences are frequent.

Acknowledgements We gratefully acknowledge to the Gujarat State Petroleum Corporation Limited (GSPC), Gandhinagar, Gujarat regarding the encouragement of research activity and providing various technical data support, and analytical support for research activity. Our 
sincere gratitude to $\mathrm{M} / \mathrm{s}$ Schlumberger India for providing software towards research work through Reservoir Characterization Centre jointly operated by Department of Applied geophysics and Department of Petroleum Engineering, IIT(ISM) Dhanbad. Authors are sincerely acknowledging to IHS Kingdom Suit for providing software towards research work. Authors are profoundly thankful to Geophysical Data Quantitative Interpretation Lab (GQIL), Department of Applied Geophysics, IIT(ISM) Dhanbad for providing necessary technical support to carry this research work.

Open Access This article is licensed under a Creative Commons Attribution 4.0 International License, which permits use, sharing, adaptation, distribution and reproduction in any medium or format, as long as you give appropriate credit to the original author(s) and the source, provide a link to the Creative Commons licence, and indicate if changes were made. The images or other third party material in this article are included in the article's Creative Commons licence, unless indicated otherwise in a credit line to the material. If material is not included in the article's Creative Commons licence and your intended use is not permitted by statutory regulation or exceeds the permitted use, you will need to obtain permission directly from the copyright holder. To view a copy of this licence, visit http://creativecommons.org/licenses/by/4.0/.

\section{References}

Adouani S, Ahmadi R, Khlifi M, Akrout D, Mercier E, Montacer M. Pore pressure assessment from well data and overpressure mechanism: case study in Eastern Tunisia basins. Mar Georesour Geotechnol. 2019. https://doi.org/10.1080/1064119X.2019.1633711.

Alam J, Chatterjee R, Dasgupta S. Estimation of pore pressure, tectonic strain and stress magnitudes in the Upper Assam basin: a tectonically active part of India. Geophys J Int. 2018;216(1):659-75. https://doi.org/10.1093/gji/ggy440.

Bhushan B. Geological survey of India, Report of the Petrographic studies of Phosphorite from Birmania area, Jaisalmer district, Rajasthan, GSI-CHQ-3562.1966

Biot MA. Theory of stress-strain relations in anisotropic viscoelasticity and relaxation phenomena. J Appl Phys. 1954;525:1385-91. https ://doi.org/10.1063/1.1721573.

Biswas SK. Regional tectonic framework, structure and evolution of the western marginal basins of India. Tectonophysics. 1987;135:37327. https://doi.org/10.1016/0040-1951(87)90115-6.

Biswas SK. Status of petroleum exploration in India. Proc Indian Natl Sci Acad. 2012;78:475-94.

Bowers GL. Pore pressure estimation from velocity data: accounting for overpressure mechanisms besides undercompaction. SPE Drill Complet. 1995;10(2):89-95. https://doi.org/10.2118/27488-pa.

Bowers GL. Detecting high overpressure. Lead Edge. 2002;21(2):1747. https://doi.org/10.1190/1.1452608.

Bowers GL. Determining an appropriate pore pressure estimation strategy. In: Offshore technology conference, Paper OTC 13042; 2001. https://doi.org/10.4043/13042-MS.

Boruah N. In: Hyderabad 2010, 8th Biennial international conference \& exposition on petroleum geophysics. Society of Petroleum Geophysicist: Rock Physics Template (RPT) Analysis of Well Logs for Lithology and Fluid Classification, p. 1-8.

Chatterjee R, Datta Gupta S, Farooqui MY. Reservoir identification using full stack seismic inversion technique: a case study from Cambay basin oilfields, India. J Pet Sci Eng. 2013;109:87-95. https://doi.org/10.1016/j.petrol.2013.08.006.

Das B, Chatterjee R. Mapping of pore pressure, in situ stress and brittleness in unconventional shale reservoir of Krishna-Godavari basin.
J Nat Gas Sci Eng. 2018;50:74-89. https://doi.org/10.1016/j.jngse .2017.10.021.

Dasgupta S, Chatterjee R, Mohanty SP. Prediction of pore pressure and fracture pressure in Cauvery and Krishna-Godavari basins, India. Mar Pet Geol. 2016;78:493-506. https://doi.org/10.1016/j. marpetgeo.2016.10.004.

Datta Gupta S, Chatterjee R, Farooqui MY. Rock physics template (RPT) analysis of well logs and seismic data for lithology and fluid classification in Cambay Basin. Int J Earth Sci. 2012;101(5):140726. https://doi.org/10.1007/s00531-011-0736-1.

Directorate General of Hydrocarbon (DGH), Rajasthan Basin, India. http://dghindia.gov.in/assets/downloads/56ceb6e098299Rajasth an_Basin_18.pdf. Accessed on 24 Feb 2017.

Eaton BA. Fracture gradient prediction and its application in oilfield operations. JPT. 1969;21(10):25-32. https://doi. org/10.2118/2163-PA.

Eaton BA. The effect of overburden stress on geopressures prediction from well logs. J Pet Technol. 1972. https://doi. org/10.2118/3719-pa.

Eaton BA. The equation for geopressure prediction from well logs. In: Society of Petroleum Engineers of AIME paper, SPE 5544; 1975. https://doi.org/10.2118/5544-MS.

Freund D. Ultrasonic compressional and shear velocities in dry elastic rock as a function porosity, clay content, and confining pressure. Geophys J Int. 1992;108:125-35. https://doi.org/10.1111/ j.1365-246X.1992.tb00843.x.

Gardner GHF, Gardner LW, Gregory AR. Formation velocity and density - the diagnostic basics for stratigraphic traps. Geophysics. 1974;39:770-80. https://doi.org/10.1190/1.1440465.

Greenberg ML, Castagna JP. Shear-wave velocity estimation in porous rocks: theoretical formulation, preliminary verification and applications. Geophys Prospect. 1992;40:195-209. https:// doi.org/10.1111/j.1365-2478.1992.tb00371.x.

Hottman CE, Johnson RK. Estimation of formation pressures from log-derived shale properties. J Petrol Technol. 1965;17(6):71722. https://doi.org/10.2118/1110-PA.

Hubbert MK, Willis DG. Mechanics of hydraulic fracturing. Pet Trans AIME. 1957. https://doi.org/10.2118/686-g.

Hussain M, Ahmed N. Reservoir geomechanics parameters estimation using well logs and seismic reflection data: insight from Sinjhoro Field, Lower Indus Basin, Pakistan. Arabian J Sci Eng. 2017;43(7):3699-715. https://doi.org/10.1007/s1336 9-017-3029-6.

Keller T, Berli M, Ruiz S, Lamande M, Arvidsson J, Schjonning P, et al. Transmission of vertical soil stress under agricultural tyres: comparing measurements with simulations. Soil Tillage Res. 2014;140:106-17. https://doi.org/10.1016/j.still.2014.03.001.

Krief MJ, Garat J, Stellingwerff J, Ventre J. A petrophysical interpretation using the velocities of $\mathrm{P}$ and $\mathrm{S}$ waves (full wave form sonic). Log Anal. 1990;31(6):355-69.

Mathew WR, Kelly J. How to predict formation pressure and fracture gradient. Oil Gas J. 1967;65(8):92-106.

Maurya SP, Sarkar P. Comparison of post stack seismic inversion methods: a case study from Blackfoot Field, Canada. Int J Sci Eng Res. 2016;7(8):1091-101.

Merey S. Estimation of fracture pressure gradients in the shallow sediments of the Mediterranean Sea by using ODP Leg 160 and Leg 161 data. J Pet Sci Eng. 2020;191:107307. https://doi. org/10.1016/j.petrol.2020.107307.

Moosavi N, Mokhtari M. Application of post-stack and pre-stack seismic inversion for prediction of hydrocarbon reservoirs in a Persian Gulf gas field. Int J Geol Environ Eng. 2016;10(8):853-62. https ://doi.org/10.5281/zenodo.1126059.

Najibi AR, Ghafoori M, Lashkaripour GR, Asef MR. Reservoir geomechanical modeling: in-situ stress, pore pressure, and mud design. 
J Pet Sci Eng. 2017;151:31-9. https://doi.org/10.1016/j.petro 1.2017.01.045.

Noori M, Gerami S, Jamali J, Alizaheh A. Pore Pressure estimation using seismic data for an Iranian Gas Reservoir. In: The 8th international chemical engineering congress \& exhibition (IChEC 2014), Kish, Iran, 24-27 February; 2014.

Oilfield review journal distributed by Schlumberger.

Pandey DK, Fürsich FT, Baron-Szabo R. Jurassic corals from the Jaisalmer Basin, west Rajasthan, India. Zitteliana. 2009a;A48/49:13-37.

Pandey DK, Fürsich FT, Sha J. Inter-basinal marker intervals-a case study from the Jurassic basins of Kachchh and Jaisalmer, Western India. Sci China Ser D Earth Sci. 2009b;52(12):1924-31. https:// doi.org/10.1007/s11430-009-0158-0.

Pennebaker ES. Seismic data indicate depth, magnitude of abnormal pressure. World Oil. 1968;166(7):73-8.

Qays MS, Wan IWY. Pore pressure prediction and modeling using well-logging data in Bai Hassan oil field northern Iraq. J Earth Sci Clim Change. 2015;6(7):290. https://doi.org/10.4172/21577617.1000290.

Reed-Hill RE, Iswaran CV, Kaufman MJ. A Power law model for the flow stress and Strain-rate sensitivity in Cp Titanium. Scr Metall Mater. 1995;33(1):157-62. https://doi.org/10.1016/0956716X(95)00152-L.
Singha DK, Chatterjee R. Detection of overpressure zones and a statistical model for pore pressure estimation from well logs in the Krishna-Godavari Basin, India. Geochem Geophys Geosyst. 2014;15(4):1009-20. https://doi.org/10.1002/2013GC005162.

Singha DK, Chatterjee R, Sen MK, Sain K. Pore pressure prediction in gas-hydrate bearing sediments of Krishna-Godavari basin, India. Mar Geol. 2014;357:1-11. https://doi.org/10.1016/j. margeo.2014.07.003.

Terzaghi K, Peck RB. Soil mechanics in engineering practice. Hoboken: Wiley; 1948.

Terzaghi K, Peck RB, Mesri G. Soil mechanics in engineering practice. 3rd ed. Hoboken: Wiley; 1996.

Zang A, Stephansson O. Stress field of the Earth's crust. 2010. https ://doi.org/10.1007/978-1-4020-8444-7.

Zhang J. Pore pressure prediction from well logs: methods, modifications, and new approaches. Earth Sci Rev. 2011;108(1):50-63. https://doi.org/10.1016/j.earscirev.2011.06.001.

Zhang Y, Yin SH. Fracture gradient prediction: an overview and an improved method. Pet Sci. 2017;14:720-30. https://doi. org/10.1007/s12182-017-0182-1.

Zhang Y, Zhang J. Lithology-dependent minimum horizontal stress and in situ stress estimate. Tectonophysics. 2017;703:1-8. https://doi. org/10.1016/j.tecto.2017.03.002. 